\title{
Automated wind turbine wake characterization in complex terrain
}

\author{
Rebecca J. Barthelmie ${ }^{1}$ and Sara C. Pryor ${ }^{2}$ \\ ${ }^{1}$ Sibley School of Mechanical and Aerospace Engineering, Cornell University, Ithaca, New York, USA \\ ${ }^{2}$ Department of Earth and Atmospheric Sciences, Cornell University, Ithaca, New York, USA
}

Correspondence: Rebecca J. Barthelmie (rb737@cornell.edu)

Received: 31 December 2018 - Discussion started: 10 January 2019

Revised: 1 June 2019 - Accepted: Accepted on 4 - Published: 28 June 2019

\begin{abstract}
An automated wind turbine wake characterization algorithm has been developed and applied to a data set of over 19000 scans measured by a ground-based scanning Doppler lidar at Perdigão, Portugal, over the period January to June 2017. Potential wake cases are identified by wind speed, direction and availability of a retrieved free-stream wind speed. The algorithm correctly identifies the wake centre position in $62 \%$ of possible wake cases, with $46 \%$ having a clear and well-defined wake centre surrounded by a coherent area of lower wind speeds while $16 \%$ have split centres or multiple lobes where the lower wind speed volumes are no longer in coherent areas but present as two or more distinct areas or lobes. Only $5 \%$ of cases are not detected; the remaining $33 \%$ could not be categorized either by the algorithm or subjectively, mainly due to the complexity of the background flow. Average wake centre heights categorized by inflow wind speeds are shown to be initially lofted (to two rotor diameters, $D$, downstream) except when the inflow wind speeds exceed $12 \mathrm{~ms}^{-1}$. Even under low wind speeds, by $3.5 D$ downstream of the wind turbine, the mean wake centre position is below the initial wind turbine hub height and descends broadly following the terrain slope. However, this behaviour is strongly linked to the hour of the day and atmospheric stability. Overnight and in stable conditions, the average height of the wake centre is $10 \mathrm{~m}$ higher than in unstable conditions at $2 D$ downstream from the wind turbine and $17 \mathrm{~m}$ higher at $4.5 \mathrm{D}$ downstream.
\end{abstract}

\section{Introduction}

\subsection{Motivation and objectives}

Temporal and spatial inhomogeneity of the flow in complex terrain (Kaimal and Finnigan, 1994) increases uncertainty in modelling and measurements of wind speed, turbulence intensity, etc., for wind resource assessment and turbine operating conditions (Sanz Rodrigo et al., 2017). They also have implications for wind turbine wake generation and propagation (i.e. formation and recovery of the volume of disturbed air that passes through the wind turbine rotor; Barthelmie et al., 2013). Most previous research on the characterization of wind turbine wakes (their meandering, merging and ultimate recovery) and evaluation of wind farm wake models and wind farm layout optimization to reduce the reduction of power and enhancement of loads on turbines operating within wind turbine wakes has focussed on applications in relatively flat terrain or offshore (Barthelmie and Pryor, 2013). However, as wind energy penetration increases, there is a need to develop improved methods for quantifying flow in complex terrain and for developing methods to optimize layouts to minimize power losses and fatigue loading from turbine-turbine interactions and wind farm wakes (Barthelmie et al., 2018; Politis et al., 2012). The advection, characteristics and ultimately the dissipation of wakes from wind turbines located in these environments are strongly dictated by flow features that are, in turn, a product of the terrain length scales and height (Kaimal and Finnigan, 1994), the presence or absence of vegetation (Finnigan and Belcher, 2004), and/or other surface heterogeneity or discontinuities (Durran, 1990). The objectives of this paper are to (i) describe observational challenges of detection and characteri- 


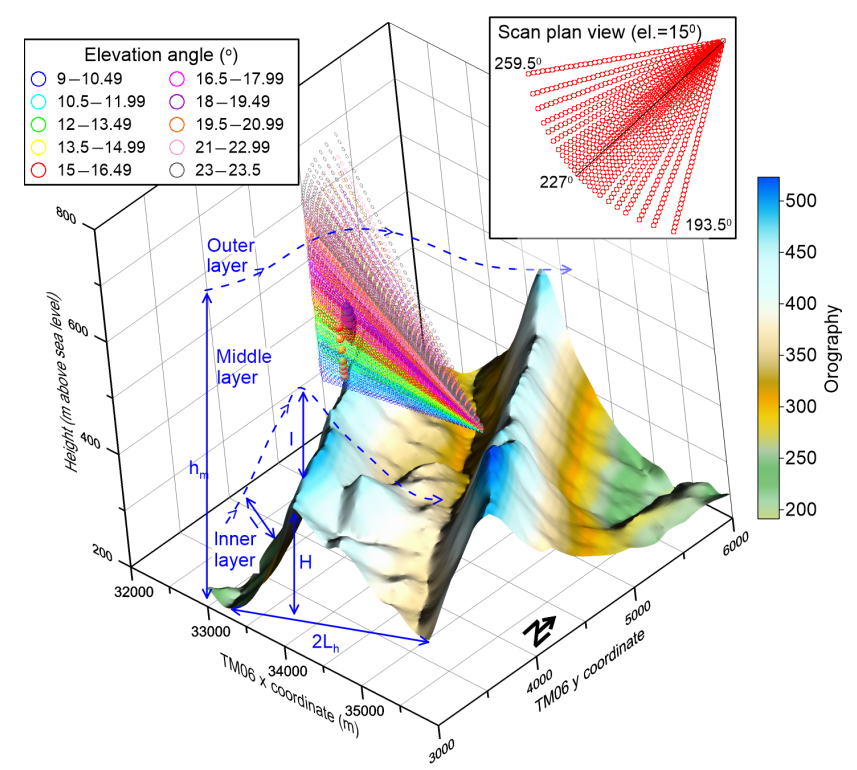

Figure 1. The orography of the Perdigão study area (shown in Portuguese TM06 coordinates with major spacing at $1 \mathrm{~km}$ ). As shown the topography is dominated by double ridges orientated northwestsoutheast. The turbine location on the SW ridge is indicated by a black disc representing the rotor plane, and the measurement heights at meteorological mast Tower 20 are indicated by the red spheres. The scan points of the arc scans from the scanning Doppler lidar located in the valley are shown for each $30 \mathrm{~m}$ range gate for 10 elevation angles from 9 to $23^{\circ}$ and 23 azimuth angles from $193.5-253^{\circ}$. The inset scan plan view shows each measurement point (range gate) for the $15^{\circ}$ elevation scan. The blue lines denote the height $(H=300 \mathrm{~m})$ and length scales $\left(L_{\mathrm{h}}=800 \mathrm{~m}\right)$ of the topography for southwesterly flow and the inner-layer height $l$ and middle-layer height $h_{\mathrm{m}}$.

zation of wind turbine wakes in complex terrain, (ii) present an automated methodology for wake centre line detection and tracking in data from scanning pulsed Doppler lidar operated in complex terrain, (iii) evaluate the automated detection when applied to data from a field experiment conducted in complex terrain, and (iv) use the objective detection of wake centre line location to examine wake behaviour from a single wind turbine as a function of the prevailing atmospheric conditions.

\subsection{Flow in complex terrain}

Flow over a hill is characterized by compression, acceleration and lifting of streamlines at the crest (Kaimal and Finnigan, 1994). In stable conditions, flow may be divided approaching the crest. If the slope is steep enough, a separation bubble forms after the crest whose depth is of the order of the hill height (Kaimal and Finnigan, 1994). Regardless of the formation of a separation bubble, a hill wake with marked velocity deficit and enhanced turbulence extends for many hill heights downwind (Kaimal and Finnigan, 1994). The near- surface flow downhill is extremely complex with modifications to the inner and outer layers, even assuming that these continue to exist, and for potential interaction with recirculation zones. For example, flow decelerates downwind of the crest, and the flow becomes detached and a separation bubble forms if the slope is steeper than $\sim 18^{\circ}$ and for smaller angles if the slope has high roughness length (Kaimal and Finnigan, 1994). Flow in the lee of the hill and/or ridge tends to be more terrain-following in stable conditions (Hunt et al., 1988), while in neutral and unstable conditions there is a recirculating vortex or separation bubble behind the hill (Ohba et al., 2002). If a separation bubble exists in stable conditions, the reattachment length is similar to that in near-neutral conditions, while the reattachment length in unstable conditions is shorter (Pieterse and Harms, 2013). The scales and dynamical properties of topographically induced flow components and their interaction with wake(s) induced by wind turbines with that flow are thus a function of the terrain dimensions (ratio of hill height $-H$ - to length scale $-L_{\mathrm{h}}$, distance from hill crest to the half height), prevailing stability, and land surface characteristics and vegetation (Fig. 1). Here we focus on flow in the metre to kilometre range at heights relevant to wind turbines (i.e. up to $\sim 150 \mathrm{~m}$ a.g.l.), accepting that flow at these scales is also impacted by phenomena at larger scales such as gravity waves and thermally generated upslope and downslope winds (Durran, 1990).

For near-neutral stability and low hills, where $H \ll L_{\mathrm{h}}$, the inner layer which is closest to the surface has height $l$ (Jackson and Hunt, 1975):

$\frac{\left(l \ln \frac{l}{z_{0}}\right)}{L_{\mathrm{h}}}=2 \kappa^{2}$,

where $z_{0}$ is the surface roughness length and $\kappa$ is the van Kármán constant. This inner layer is typically assumed not to extend beyond the constant stress (surface) layer and to have a height $l<0.2 \delta$, where $\delta$ is the boundary-layer height. The inner-layer height increases as $z_{0}$ increases, but for a range of likely roughness lengths, $z_{0}=0.01$ to $0.5 \mathrm{~m}$ and $L_{\mathrm{h}}=800 \mathrm{~m}$, $l$ is $\sim 32$ to $60 \mathrm{~m}$. Assuming a logarithmic wind profile (and thus neutral stability), the middle-layer height, $h_{\mathrm{m}}$ (i.e. lowest height of the outer layer; see Fig. 1), can be defined using (Coppin et al., 1994)

$h_{\mathrm{m}} \ln ^{1 / 2}\left(L_{\mathrm{h}} / z_{0}\right)=L_{\mathrm{h}}$,

where typically (Coppin et al., 1994)

$l / h_{\mathrm{m}} \leq 0.1$.

For $L_{\mathrm{h}}=800 \mathrm{~m}$ and $z_{0}$ values given above, $h_{\mathrm{m}}$ is in the range 238-295 m.

These approximations can be extended to include the influence of stability. While noting the limitations on use of similarity theory in complex terrain, using the Monin-Obukhov 
length $L$ to describe local stability conditions (Kaimal and Finnigan, 1994),

$$
L=\frac{\overline{\theta_{\mathrm{v}}} u_{*}^{3}}{\kappa g \overline{w^{\prime} \theta_{\mathrm{v}}^{\prime}}},
$$

where $\overline{\theta_{\mathrm{v}}}$ is the virtual potential temperature, $u_{*}$ is the friction velocity, $g$ is acceleration due to gravity and $\overline{w^{\prime} \theta_{v}^{\prime}}$ is the sensible heat flux (Stull, 1988). The height of the inner layer is then given by (Coppin et al., 1994)

$$
\frac{l}{L_{\mathrm{h}}}=2 \kappa^{2}\left[\ln \left(\frac{l}{z_{0}}\right)+\psi_{m}\left(\frac{1}{L}\right)\right]^{-1} \text {. }
$$

For $z_{0}=0.3 \mathrm{~m}, l$ varies from about $50 \mathrm{~m}$ in near-neutral conditions to $42 \mathrm{~m}$ in stable conditions, increasing to about $63 \mathrm{~m}$ in unstable conditions (Table 1).

The top of the middle layer, $h_{\mathrm{m}}$, in stable conditions (Kaimal and Finnigan, 1994) is given by

$h_{\mathrm{m}} \sim L_{\mathrm{h}}\left[\ln \left(\frac{h_{\mathrm{m}}}{z_{0}}\right)+5\left(\frac{h_{\mathrm{m}}}{L}\right)\right]^{-1 / 2}$,

and in unstable conditions (Coppin et al., 1994), it is given by

$h_{\mathrm{m}} \sim L_{\mathrm{h}}\left[\frac{\left(1-15 \frac{h_{\mathrm{m}}}{L}\right)^{-1 / 4}}{\left(\ln \left(\frac{h_{\mathrm{m}}}{z_{0}}\right)+\psi_{m}\left(\frac{h_{\mathrm{m}}}{L}\right)\right)}\right]^{1 / 2}$.

These approximations imply that for a wind turbine on a low hill, with the lowest tip $\sim 40 \mathrm{~m}$ and highest tip $\sim 120 \mathrm{~m}$, the flow impacting the turbine rotor may be inside, close to or above the inner layer, depending on the terrain height or length scale or roughness, and also extends into the middle layer. For reasonable conditions (e.g. $z_{0}=0.01$ to $0.5 \mathrm{~m}$; $L_{\mathrm{h}}=800 \mathrm{~m}$ ) that prevail in many currently operational landbased wind farms, the inner layer will intersect the rotor plane; thus this layer has importance for both the inflow to wind turbines and their wakes. The middle layer will have greatest relevance for the propagation and dispersion of wind turbine wakes at least in the near wake (Table 1). Conversely, the outer layer (i.e. flow at heights above $h_{\mathrm{m}}$, and thus the large-scale flow) is generally of lesser importance to wind turbine wake generation, propagation and characteristics, depending on the terrain characteristics.

Consistent with the above, siting wind turbines in complex terrain usually involves placement of the turbines close to and at the top of ridges where there is maximum speed-up and hence maximum topographic enhancement of the wind resource (Barthelmie et al., 2016a). For homogeneous flow oriented perpendicular to a ridge (Barthelmie et al., 2016a) or at shallow yaw angles from the perpendicular (Barthelmie and Pryor, 2018), this speed-up $\Delta S$ (defined as the location wind speed $U_{(x, z)}$ minus the free-stream wind speed $U_{(0, z)}$ normalized by $\left.U_{(0, z)}\right)$ is quantified as

$\Delta S_{(x, z)}=\frac{U_{(x, z)}-U_{(0, z)}}{U_{(0, z)}}$.

It has its maximum close to the ridge top at heights relatively close to the surface, decreases with height and is larger in conditions with stable stratification (Emeis et al., 1995). Assuming that $\Delta S$ is maximum at a height of $l / 3$ (i.e. onethird of the inner-layer height, see below; Kaimal and Finnigan, 1994), under the near-neutral stability maximum, $\Delta S$ $\left(\Delta S_{U \text { Max }}\right)$ will typically be observed between $14-21 \mathrm{~m}$, although it is worth noting that under different stability conditions,

$\Delta S_{U \operatorname{Max}}=\frac{H}{L_{\mathrm{h}}}\left[\frac{\bar{U}_{0\left(h_{\mathrm{m}}\right)}^{2}}{\bar{U}_{0(l)} \bar{U}_{0(l / 3)}}\right]\left[1+\frac{1.8}{\ln \left(\frac{l}{z_{0}}\right)}\right]$,

or for different height and/or length scales, the speed-up may also impact the flow in the middle layer $\left(h_{\mathrm{m}}>z>l\right)$, where $\varepsilon$ is approximately equal to 1 depending on the hill shape (Coppin et al., 1994):

$\Delta S_{(x, z)}=\frac{H}{L_{\mathrm{h}}}\left[\frac{\bar{U}_{0}^{2}\left(h_{\mathrm{m}}\right)}{\bar{U}_{0}^{2}(z)}\right] \varepsilon$.

As illustrated by this introduction, placement of wind turbines in complex terrain represents a substantial challenge for efforts to both characterize wind turbine wakes and thus turbine-turbine interactions due to the complexity of the flow field in which they are embedded and to developing robust tools to optimize the layout of large arrays in inhomogeneous environments (Politis et al., 2012).

The topography in the location of the experiment considered herein is dominated by two parallel ridges of almost equal height (Fig. 1; Fernando et al., 2019; Letson et al., 2019). Flow in this environment is further complicated by the presence of anabatic or katabatic and upslope or downslope flow patterns that result from (i) thermal forcing where within-valley winds are defined by local pressure gradients and flow can be detached from winds above, especially under conditions of weak larger-scale forcing, (ii) strong downward momentum transfer from either vertical turbulent transport or gravity waves (i.e. this can occur in either unstable or stable conditions), (iii) wind in geostrophic balance being channelled by the valley producing an along-valley wind component, and (iv) pressure-gradient channelling producing winds along the valley (Whiteman and Doran, 1993).

\subsection{Characterizing wind turbine wakes}

Virtually all wind turbines are installed in wind farms (i.e. multi-turbine arrays) where the interaction of the lower velocity air directly downstream from a wind turbine (wake) on its nearest neighbour reduces the wind speed, and hence 
Table 1. Inner-layer $(l)$ and medium-layer heights $\left(h_{\mathrm{m}}\right)$ for southwesterly flow to the wind turbine at Perdigão (see Eqs. 1-7).

\begin{tabular}{lrrrrrrrrr}
\hline & Near neutral & Stable & Unstable & Near neutral & Stable & Unstable & Near neutral & Stable & Unstable \\
\hline$z / L(z=78 \mathrm{~m})$ & & 0.16 & -0.16 & & 0.08 & -0.08 & & 0.16 & -0.16 \\
$z_{0}(\mathrm{~m})$ & 0.3 & 0.3 & 0.3 & 0.3 & 0.3 & 0.3 & 0.1 & 0.1 & 0.1 \\
$L_{\mathrm{h}}(\mathrm{m})$ & 800 & 800 & 800 & 800 & 800 & 800 & 800 & 800 & 800 \\
$l(\mathrm{~m})$ & 50 & 46 & 64 & 50 & 50 & 63 & 42 & 37 & 52 \\
$h_{\mathrm{m}}(\mathrm{m})$ & 284 & 261 & 262 & 284 & 227 & 240 & 266 & 220 & 232 \\
\hline
\end{tabular}

the power output, and increases the fatigue loading by increasing the turbulence intensity. Average power losses from large wind turbine arrays due to wind turbine wakes are reported to be $2 \%-4 \%$ on land (El-Asha et al., 2017) and can be $10 \%-20 \%$ offshore (Barthelmie et al., 2007). At offshore sites the principal determinant of wake intensity is the freestream wind speed which determines the thrust coefficient of the wind turbine with large relative velocity deficits between cut-in and rated wind speeds (i.e. from $\sim 3-12 \mathrm{~ms}^{-1}$ ) responding to high thrust coefficients (Barthelmie et al., 2013). As wind speeds increase, thrust coefficients decrease and the relative magnitude of the wake velocity decreases. Secondary drivers that also determine power losses due to wind turbine wakes include wind direction (that determines spacing between turbines and can be associated with particular atmospheric stability climates or flow regimes; Barthelmie, 1998), turbulence intensity and atmospheric stability (Barthelmie et al., 2013).

In flat terrain under near-neutral stability, the wake expansion rate (and thus the volume of air with reduced momentum) is assumed to follow (Jensen, 1983)

$D_{\mathrm{w}}=D_{0}+2 k X$

where $D_{\mathrm{w}}$ is wake width in rotor diameters $(D), D_{0}$ is the initial wake width, $k$ is the rate of expansion $(0.075$ is recommended in the Wind Atlas Analysis and Application Program - WAsP - for land sites; Katic et al., 1986), which is determined by the factors listed above such as ambient turbulence intensity, and $X$ is the distance downstream. Assuming that for most wind turbines $D \sim$ hub height (WTHH - wind turbine hub height), the wake expands to $2 D$ and hence will impact the ground at approximately $6.6 \mathrm{D}$ downstream of the wind turbine (Fig. 2). As the wake expands and higher-momentum air is drawn into the wake the velocity deficit decreases such that practically it is difficult to determine the presence and characteristics of wakes from individual wind turbines beyond about $10 \mathrm{D}$ downwind, except in stable stratification and/or low surface roughness conditions when the expansion and meander are more limited. Large wind farm (multiple) wakes can be detected over longer distances (Pryor et al., 2018), particularly in offshore conditions where the generally smooth surface and low-turbulence intensity leads to both the deep array effect within arrays and highly persistent whole array wakes (Christiansen and Hasager, 2005; Barthelmie and Jensen, 2010).

Wakes are advected by the ambient flow, and thus, in addition to expanding, they are also subject to both horizontal and vertical meander (Larsen et al., 2008). Although many simple models assume the wake to be axisymmetric around the wind turbine hub height (Jensen, 1983), both shear and veer in the inflow cause wakes to become highly asymmetric (Bodini et al., 2017; Barthelmie et al., 2016b), and this effect is amplified in stable conditions when the boundary layer is shallower, at least in flat terrain (Abkar and Porte-Agel, 2016). Large eddy simulation results indicate that shape of the wake and the maximum velocity deficit moving downstream are also impacted by the Coriolis force (Abkar and Porte-Agel, 2016). While the majority of both analytical and numerical models broadly capture wake features such as wake velocity deficit (especially for single wakes; Ainslie, 1988), it has proved difficult to improve predictive models that quantify wake details in large offshore wind farms (Barthelmie et al., 2004) or the net effect on the downstream atmosphere from large onshore arrays (Pryor et al., 2018) due both to wake complexity and a shortage of available wake measurements for model evaluation.

Complex terrain typically has higher $z_{0}$ and thus higher ambient turbulence intensity which may lead to faster wake recovery, particularly if enhanced by unstable conditions (Han et al., 2018). Depending on the topography and the external conditions (wind speed, stability and turbulence), wakes can either follow the terrain slope or be lofted (defined here to mean that the wake centre is above the height of the horizontal line of the wind turbine hub height) at or slightly downwind of hill crests (Fig. 2). The wake shape is modified by the movement of the wake downhill with the wake centre height following the slope, but the location and shape of the wake are also modified by the turbulence intensity (Politis et al., 2012). The wake from the wind turbine will also interact with, and be modified by, the hill wake. It is likely that the impact of the topography on the wake at the study site considered herein (Perdigão) is even more profound and complex than these previous studies due to the multi-scale topographic, thermal and canopy influences on flow and wake behaviour. 
(a)

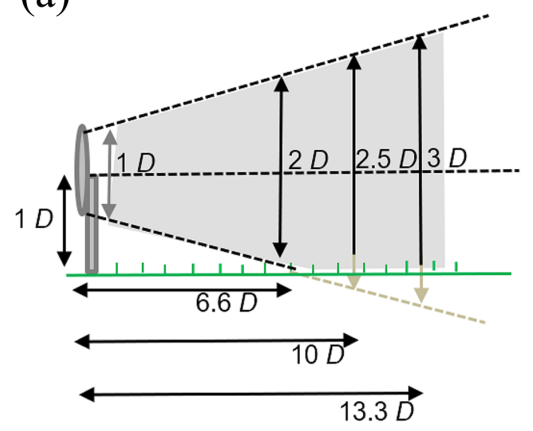

(b)

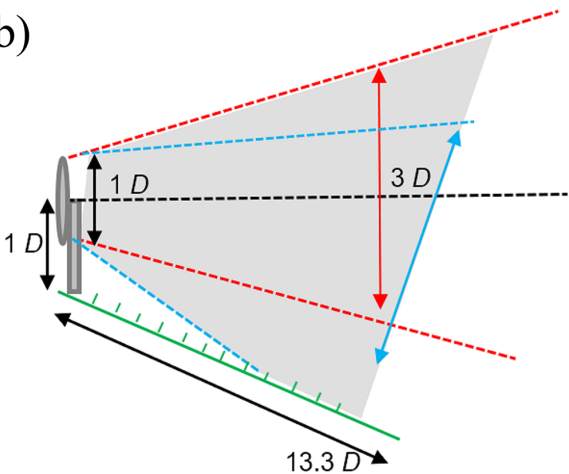

Figure 2. Schematic of wind turbine wake expansion downwind and the scanning volume needed (grey shading) in near-neutral conditions, with the horizontal wake centre line being shown by the black dashed line. (a) In flat terrain, for $k=0.075$, the wake can be expected to impact the ground at 6-7 D downwind. (b) In complex terrain, e.g. for a turbine placed at a ridge, the wake can follow the terrain (indicated in blue) or be lofted (indicated in red); hence the scanning volume required in order to detect and characterize wakes is much larger.

\subsection{Remote sensing of flow and wakes}

Remote-sensing approaches, particularly application of lidars, are increasingly being leveraged to provide flow characterization for the wind energy industry (Risan et al., 2018; Mikkelsen et al., 2008; Berg et al., 2015) and can be used to characterize the three-dimensional wake volume as it evolves downwind from the wind turbine as well as to provide concurrent free-stream wind speeds from upstream measurements (Barthelmie et al., 2014, 2018). Doppler lidar deployed for wake characterization can either be installed on the wind turbine nacelle, where it has been shown to be effective for characterizing individual wakes from 2-6 D (Aitken and Lundquist, 2014), or on the ground relatively close to the wind turbine (Doubrawa et al., 2016) or at a distance scanning towards the wake(s) (Torres Garcia et al., 2017; Barthelmie et al., 2014). It is frequently difficult to get permission to install a Doppler lidar on the nacelle, and there is often a desire to sample wakes from multiple wind turbines simultaneously; thus most field campaigns for quantification of wind turbine wake characteristics involve Doppler lidar placed on the ground as shown here (Barthelmie et al., 2014; El-Asha et al., 2017; Iungo et al., 2013; Clifton et al., 2018). Most frequently used scanning patterns comprise one or more arc scans (in each arc scan the scan elevation angle is held constant while the azimuth angle is varied - i.e. it is a pseudo plan position indicator, or PPI, scan in which the azimuth angle $<360^{\circ}$ ), range height indicator (RHI) scans (varying elevation, fixed azimuth angle), and/or a vertical azimuth display (VAD; high-elevation angle, $360^{\circ}$ scan at fixed azimuth angles). Determining the ideal location for scanning Doppler lidar and designing the scanning geometry to optimally sample the wind turbine wake(s) rely on detailed knowledge of the wind climate, including prevailing wind direction (recall of lowest uncertainty in retrieved radial velocities is achieved when the line of sight is aligned with the wind direction, and error increases with increasing angular offset; Wang et al., 2016), and are also constrained by practical considerations such as the availability of a secure and reliable electricity supply, security, data and personnel access, and so on.

Subjectively identifying the presence of wind turbine wakes using data acquired from scanning Doppler lidar deployed in flat terrain is relatively straightforward, but using scanning Doppler lidar to objectively detect and track the wake centre line and quantify wake metrics is more challenging. Most research focussed on lidar-based wake characterization has employed case studies, either because the field campaign is relatively short, providing only a few cases (Banta et al., 2015), or because it is difficult to automate the process of identifying and quantifying wake deficits, shapes, meander and so forth (Bodini et al., 2017). Adding to the challenges of multiple wake characterization, the behaviour of wakes in complex terrain is more difficult to both measure and model, and important supporting information such as atmospheric stability and turbulence intensity that has direct and measurable effects on changes in power production due to wakes (Barthelmie and Jensen, 2010) is frequently only available from a limited number of instruments deployed on meteorological masts (Machefaux et al., 2016).

\section{The Perdigão field experiment}

The current research reports measurements from the largest field experiment in boundary-layer meteorology undertaken to date at the complex terrain site Perdigão in central Portugal (Fig. 1). It is part of a series of experiments undertaken within the New European Wind Atlas project designed to improve characterization of wind resources and operating conditions for the wind energy industry using high-resolution, high-fidelity observations of boundary-layer flow from both traditional meteorological platforms and remote-sensing in- 
struments such as ground-based Doppler lidars (Mann et al., 2017).

The Perdigão study area is dominated by two parallel ridges oriented northwest to southeast, separated by approximately $1.6 \mathrm{~km}$ (peak to peak), and with lateral extent of $>4 \mathrm{~km}$ (Fig. 1). The ridges extend $300 \mathrm{~m}$ above the local terrain and about $170 \mathrm{~m}$ above the central valley. A single 2 MW Enercon E-82 wind turbine (hub height - WTHH - of $78 \mathrm{~m}$ and a rotor diameter $-D-$ of $82 \mathrm{~m}$ ) is deployed on the southwest ridge (Fig. 1). At this location the ridge has an approximate height $(H) \sim 300 \mathrm{~m}$ and $L_{\mathrm{h}}=800 \mathrm{~m}$. Slopes from the central valley towards the wind turbine have an average value of $16 \%$ but are steep near the valley base $(\sim 30 \%)$, gentler in the middle portion, and then increase to $40 \%$ and $>60 \%$ in the last few tens of metres at the ridge top (Fig. 1). The land cover and canopy is also heterogenous, with areas of grass and low vegetation in the valley transitioning to coniferous trees on the lower slopes and then mainly eucalyptus trees or bare areas and low shrubs close to and along the ridge. For the terrain specifications of Perdigão and flow from the southwest (i.e. inflow for wind turbine and thus wakes that potentially will enter the Galion lidar scanned volume), the inner and middle-layer heights of $l \sim 50 \mathrm{~m}$ (Eq. 1) and $h_{\mathrm{m}} \sim 284 \mathrm{~m}$ (Eq. 6) for near-neutral stability and with $z_{0}$ are assumed to be either 0.3 or $0.1 \mathrm{~m}$ (Table 1). This implies that at least part of the wind turbine wake will lie within the inner layer and will be strongly impacted by the surface characteristics.

The main Perdigão field experiment ran from mid-January to the beginning of July 2017. During the experiment sonic anemometers and other micrometeorological instruments were deployed at heights of 10 to $100 \mathrm{~m}$ on 50 fixed meteorological masts. In addition to the meteorological masts, multiple Doppler lidars and sodars were operated during the entirety of the main experiment, and many other instruments were deployed during the intensive operating period (IOP) from 15 May-30 June 2017 (Fernando et al., 2019).

Meteorological conditions close to the wind turbine are summarized herein using $18 \mathrm{~Hz}$ data collected using a Gill WindMaster Pro sonic anemometer deployed at $z=$ $78 \mathrm{~m}$ a.g.l. on Tower 20 (a $100 \mathrm{~m}$ meteorological mast) on the southwest ridge displaced approximately $180 \mathrm{~m}$ southeast of the wind turbine (see further details of the flow variability across the site given in Fernando et al., 2019, and Letson et al., 2019). In the analysis of wake centre line behaviour under different prevailing atmospheric conditions, atmospheric stability close to the wind turbine is represented by the MoninObukhov length $L$ (Eq. 4) determined from the $78 \mathrm{~m}$ sonic anemometer measurements in each $10 \mathrm{~min}$ period and allocated to a stability class based on $z / L$, where $z / L<-0.08$ is unstable, $-0.08<z / L<0.08$ is near neutral and $z / L>0.08$ is stable (Barthelmie, 1998). The inflow turbulence intensity (TI) in each $10 \mathrm{~min}$ period is computed from the same sonic anemometer measurements as

$\mathrm{TI}=\frac{\sigma_{U}}{U}$.

Wake detection for the entire period of operation of the scanning pulsed Doppler lidar operated by Cornell University (mid-January and the end of June 2017) is presented herein. However, data from Tower 20 are only available from March; thus the characterization of wake centre position as a function of prevailing meteorology can only be considered for March-June, inclusive. The Galion 4000 lidar has a wavelength of $1.56 \mu \mathrm{m}$, a pulse length of $30 \mathrm{~m}$ and a range of up to $4 \mathrm{~km}$ (Wang et al., 2015). The instrument was operated from $980 \mathrm{~m}$ northeast of the wind turbine at a location in the central valley (Fig. 1). Pre-deployment planning focussed on development of an optimal scanning geometry for the scanning Doppler lidar sufficient for acquiring a data set to rigorously evaluate an objective processing methodology and to provide quantitative metrics of the location and characteristics of wind turbine wakes in complex terrain. The scan configuration described below is thus designed to permit continuous autonomous operation in the long-term period and balance having sufficiently high-density scans to permit identification of the wake (in both the time and space domains) while not defining too small an overall arc span that would preclude collection of a meaningful number of cases. This measurement strategy was informed by the wind climatology for the site, and results from the test experiment Perdigão 2015 (Vasiljević et al., 2017) indicated that the streamline deformation at and downwind of the ridge is highly variable and associated with a wide range of wake behaviour, including lofting and descending, and follows the terrain. In the following Sect. 3, the creation of the scanning geometry and development of the automated processing algorithm are described.

\section{Methodology for automated wake detection in complex terrain}

\subsection{Defining lidar scan geometry}

For a scanning Doppler lidar with a relatively slow-moving head (such as the Galion used here) design of a scan geometry that integrates a combination of arc, RHI and VAD scans requires consideration of a range of temporal and spatial factors including the following:

- Capturing the wind turbine wake with a sufficient spatial detail and number of repetitions to derive statistically robust information requires assumptions regarding the prevailing wind direction in order to limit the arc span (i.e. range of arc azimuth angles).

- Selecting low-elevation angles for arc scans allows the lower portion of the wake to be observed as the wake expands and then potentially impacts the ground and also 
minimizes errors in transforming radial velocity into Cartesian wind speed coordinates. For a Doppler lidar placed close to the wind turbine, selecting low-elevation angles will not allow the wake top to be measured, while choosing elevation angles that are higher will allow the beams to measure across the near wake but then will scan beyond the wake top after short distances. Assuming that the Doppler lidar is placed at the turbine base for the case in Fig. 2a, a scanning angle of $17.6^{\circ}$ is required to scan to the top of the wake at $6.6 \mathrm{D}$, and, assuming a standard expansion rate, this would cover the top of the wake to $10 \mathrm{D}$ distance. For a Doppler lidar placed at a distance scanning towards the wind turbine, low-elevation angles and a clear line of sight are needed. For example, after $1 \mathrm{~km}$ an elevation angle of $2^{\circ}$ will already have attained a height of $35 \mathrm{~m}$, and an angle of $4^{\circ}$ would have a height of $70 \mathrm{~m}$. Hence to capture the whole wake area in a vertical slice, careful planning is needed for proper selection of the elevation angles.

- Using a wide arc span can reduce uncertainties in flow characterization from Doppler lidar (Wang et al., 2016) and may capture a wider range of possible wake tracks but increases the scan time, thus decreasing the possible temporal resolution.

- Reducing the number of range gates limits the maximum horizontal range but decreases the dwell time for each individual azimuth and elevation angle, affording the opportunity for decreased disjunct sampling duration (i.e. decreases the time between a specific volume being resampled).

- Selecting sufficient elevation angles is necessary for providing sufficient detail of the wake at various heights and distances (Doubrawa et al., 2017), but increasing the number of elevation angles increases the disjunct time interval.

- RHI scans can provide vertical slices through the wake as it moves downstream, but if incorrectly aligned, they will produce "empty" scans, i.e. scans of the wind field without wakes, unless wake tracking is employed (Wildmann et al., 2018).

- Vertical azimuth display (VAD) scans are useful for determining wind direction as well as providing a consistent time series at a range of heights, albeit for one location, but again inclusion of VAD scans can compromise inclusion of additional arc scans and/or lead to longer disjunct time increments.

Additional challenges for experiments in complex terrain include the following:

- If there is a need to retrieve wind speed components from the Doppler radial velocities generated from a single lidar, it is necessary to assume homogeneity within the scanned volume (Wang et al., 2016); these criteria are unlikely to be realized in complex terrain (Pauscher et al., 2016).

- It is common practice to define wind turbine wake characteristics relative to a single free-stream inflow profile and/or undisturbed downstream profile(s). While previous studies have invoked the concept that a wind turbine wake is a feature embedded in a logarithmic wind profile and have used that to define wind turbine wake characteristics (Aitken et al., 2014), vertical profiles in complex terrain with heterogeneous land use/land cover differ markedly from this assumption. However, deriving representative free-stream wind speed profile(s) is difficult in complex terrain, and it will also be more difficult to measure one or more upstream wind speed profiles, depending on the terrain and scanning Doppler lidar location. The horizontal and vertical complexity of the flow may mean that there is no one wind speed or turbulence intensity profile that is representative of inflow conditions across the rotor plane during a $10 \mathrm{~min}$ period, and this will result in increased uncertainty in the derived wake characteristics.

- Wakes in complex terrain exhibit a more diverse range of behaviours than in flat terrain (as illustrated in Fig. 2a) because they are embedded in flow where there may be very strong shear and/or veer, and the streamlines may closely follow the terrain or may exhibit vortex structures and zones of attachment or detachment. The scan geometry must be designed in a manner that can capture wakes that exhibit negative and positive vertical displacement from the original axis of generation. Accordingly, as indicated in Fig. 2b, the scanned volume will need to be larger than in flat terrain. Furthermore, it is likely that the turbulence intensity will be relatively high and wakes will not be preserved over long distances as they are offshore (Barthelmie et al., 2013).

These points serve to illustrate the issues in finding a scanning geometry with both sufficient spatial and temporal resolution. For Perdigão, the number of scan types employed for use in the scanning Doppler lidar is limited to optimize wake capture, ensure that the disjunct sampling did not extend beyond $10 \mathrm{~min}$ (i.e. that the full scan is completed in $10 \mathrm{~min}$ ) and reduce the complexity of the data processing. A schematic of the final version of the scan geometry designed for the Perdigão campaign is shown in Fig. 1. It comprises a series of 10 fixed elevation arc scans with telescoping (i.e. variable intervals) in both the vertical and azimuth close to the direct alignment with the wind turbine. Elevation angles are $9,10.5,12,13.5,15,16.5,18,19.5,21$ and $23^{\circ}$. The arc angle in the azimuth varies with the elevation angle. For $10.5^{\circ}$ elevation and above, it comprises 23 beams from 199 to $259^{\circ}$, with resolution between 1.5 and $6^{\circ}$ (Fig. 1). For $9^{\circ}$ elevation, some of the outermost angles were removed because 
they returned very few data once vegetation had grown during spring. At the end of each scan 3-4 VAD scans (azimuth angle is $0: 30: 360$; elevation angle is $56^{\circ}$ ) are included to allow an initial estimation of direction and wind speed at a height equal to the wind turbine to be determined and provide a vertical profile of wind speeds within the valley for use in other research. Minor adjustments were made to the scan pattern in February 2017 to improve the efficiency of the scan, including reducing the number of range gates to 41 , making the maximum distance scanned $1230 \mathrm{~m}$. In May 2017 the lowest elevation angle of $7^{\circ}$ was removed because it was frequently blocked by vegetation, and additional RHI scans directly towards the wind turbine at $\sim 227^{\circ}$ (azimuth: 226.9 and $227.4^{\circ}$ ) were added for comparison with other lidar data sets from the IOP (Barthelmie et al., 2018; Wildmann et al., 2018). These modifications were kept to a minimum to ensure continuity in the subsequent data analysis.

\subsection{Quantifying free-stream conditions}

A description of the free-stream (i.e. inflow) conditions is critical for subsequent wake metric determination and also subject to high uncertainty, particularly in complex terrain. For a single wake in flat terrain or offshore, the freestream wind speed can be assumed to be a single-location wind speed immediately upstream of the wind turbine at the turbine hub height or a simplified wind speed profile (Barthelmie et al., 2010). However, as rotor planes increase in size or as flow veers and shears in complex terrain, it becomes increasingly difficult to accurately describe the inflow profile. Although there is a meteorological tower (Tower 20) located $180 \mathrm{~m}$ along the ridge from the wind turbine, there are issues with using this, as the free-stream wind speed and direction, due to the acceleration and turning of the flow at the ridge and the spatial variability of the inflow wind field (Menke et al., 2019). Furthermore, the intention of this research is to develop a process in which a single scanning pulsed Doppler lidar could be deployed without additional instrumentation and operated autonomously to detect and characterize wind turbine wakes. Thus, an additional consideration for the scan geometry definition and data processing is to include a sufficient number of range gates to allow characterization of the free-stream winds that impinge upon the rotor plane.

In the analyses presented herein the process for identifying potential wind turbine wakes cases that may have been sampled by the Galion lidar is multi-step. The VAD scans are used for the initial screening because they are much faster in processing and determining whether there can potentially be a measured wake, depending on the wind speed and direction. First, the approximate wind speed and direction at a height above the Galion lidar equal to the WTHH $\pm 30 \mathrm{~m}$ are estimated from the VAD scans as the maximum negative mean value of all valid radial velocities (where a signal-tonoise threshold - SNR - of 1.015 is applied) within each
10 min period. If this analysis also indicated a wind direction of $210^{\circ}$ or $240^{\circ}$ (i.e. flow from the wind turbine toward the scanning lidar), the processing continues using the larger volume of the arc scans from the same 10 min period. Arc scan radial velocities $(\mathrm{SNR}>1.015)$ at a range of the distance to the WTHH $+40 \mathrm{~m}$ and for scans at an elevation angle of $12-17^{\circ}$ are used to refine the estimated inflow wind direction and wind speed. However, for some periods with low clouds or rain there are insufficient returned wind speeds at this distance $(\sim 1 \mathrm{~km})$ to proceed. A comparison of the wind speed and direction as derived from sonic anemometer data collected at $78 \mathrm{~m}$ on Tower 20 and the radial wind speed and direction calculated from arc scans for a height equal to the WTHH $\pm 40 \mathrm{~m}$ is shown in Fig. 3. Although there is a consistent relationship between the independent measurements of wind speed and direction close to the wind turbine from the sonic anemometer and the lidar with, for example, a linear fit of wind speeds yielding an intercept of $<0.5 \mathrm{~ms}^{-1}$ and a slope of 0.94 , there is also considerable scatter. There is less good agreement for wind direction. There are three main reasons for the scatter beyond the spatial offset between the mast-based "point" measurements and the use of the average direction from the arc scan (Fig. 3): (i) the discretization of wind directions from the lidar is a function of the scanned azimuth angles, (ii) there are fundamental differences in volume-average observations from lidars and sonic anemometers (Wang et al., 2015), and (iii) there is heterogeneity in flow conditions along the ridge and turning of the flow as it summits the crest of the hill (see, for example, Fig. 4 in Vasiljević et al., 2017). For this reason, the inflow wind speed and direction derived from the Galion lidar are used only to set a flag that indicates that a wind turbine wake is likely to be present within the volume scanned by the scanning Doppler lidar (i.e. wind speeds are above the cut-in for the wind turbine, and the wake is likely to be propagated into the sampled volume).

\subsection{Scan processing for identification of possible wake cases}

As the volume of data sets being collected from remotesensing devices for wind turbine wake analyses increases there is a need to transition from manual analyses of case studies to automated procedures capable of generating statistically robust ensembles. The objective of the scan processing is thus to develop an algorithm that can detect the presence of wakes while rejecting non-wake cases and can derive quantitative wake metrics, including the focus here of centre location, with sufficient fidelity and detail that they can be used to describe the statistical properties of wind turbine wakes with increasing downwind distance from the wind turbine(s). In the following, radial velocities are given to avoid introducing errors or artefacts associated with the transformation into Cartesian coordinates. The objective is to create an algorithm that can detect and quantify wake features in 

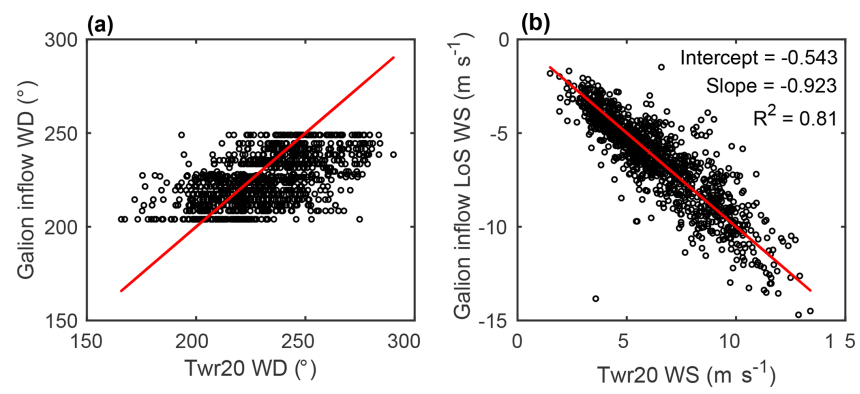

Figure 3. Comparison of $10 \mathrm{~min}$ (a) inflow wind direction and (b) inflow wind speed at $78 \mathrm{~m}$ height from scanning Doppler lidar measurements (labelled Galion inflow) and those from the sonic anemometer deployed at $78 \mathrm{~m}$ on Tower 20 (shown as Twr20). Note that the wind speeds reported by the Galion are radial line of sight velocities and are negative for flow towards the wind turbine. $1: 1$ lines are shown in red, while each dot represents a $10 \mathrm{~min}$ period $(n=1123)$.

long-term measurements, even in complex terrain where the minimum velocity is not always observed in the wake and the flow is affected by recirculation (Menke et al., 2019).

As shown in Fig. 4, an algorithm is developed and applied to data from Perdigão that starts with assessment of the status and fast processing of the VAD scans for an initial determination of the possibility of wakes. It would naturally be useful to incorporate SCADA data to ascertain the operational state of the wind turbine, but these are not available. If the case passes this criterion an evaluation of the direction and radial wind speed from the arc scans is made close to the wind turbine location to determine whether a wake is likely to be present and whether it is being advected in a direction sampled by the arc scan volumes (see an example of the arc scans in Fig. 5). Then for each of the downstream distances considered (i.e. the vertical planes located at 2, 2.5, 3, 3.5, 4 and $4.5 \mathrm{D}$ ), an assessment is made of whether there are sufficient retrieved radial wind speeds (i.e. measurements with a SNR > 1.015) to describe both the presence of a wake and the background flow field for each downstream distance and height. Once each case has passed these filters, radial wind fields on these planes are used to derive anomaly fields (see Sect. 3.4) from which the wake centre location is identified and other wake metrics are calculated for each downstream distance. The wake centre is calculated using both original data and fields interpolated by the cubic spline. Hence this data set and the wake detection is entirely self-contained. The performance of the algorithm in determining the wake centre line location is discussed in the Results section.

\subsection{Wake characterization}

One of the main issues in wake research is in developing objective techniques to identify and quantify wake features (Aitken et al., 2014). Most previous field research has been in relatively flat terrain (Smith et al., 2013) or offshore
(Barthelmie et al., 2013), and even in these environments it is very challenging to characterize wakes quantitatively (ElAsha et al., 2017). Understanding the background flow field in which the wake(s) is (are) embedded is critical for defining spatial and temporal variability of wake length scales, velocity and shape evolution with distance (Barthelmie et al., 2010; Doubrawa et al., 2016). In future work quantitative methods will be developed and applied to the full set of wake measurements from our complex terrain site in order to find robust yet sensitive methods that can be applied routinely to quantify wake characteristics. Herein, we focus on automated identification of the wake centre location and use of the automated detection algorithm to characterize variations in the wake trajectories as a function of the prevailing meteorology.

As discussed above, a description of the undisturbed flow field is necessary for use in identifying the location of the wake centre line and defining wind turbine wake characteristics such as the velocity deficit $\left(v_{\mathrm{d}}(x, z)\right)$ :

$v_{\mathrm{d}(x, z)}=U_{0(x, z)}-U_{(x, z)}$,

where $v_{\mathrm{d}}$ is the velocity deficit and $U_{0}$ is the background flow field velocity. Defining both the $U_{0}$ and $U$ in the $x, y$ and $z$ directions is the primary challenge in wake detection and characterization in complex terrain. The approach adopted here is to define these properties on planes at six fixed downstream distances from the wind turbine (i.e. $y$ is set to 2, 2.5, 3, 3.5, 4 and 4.5 D). At each of these downstream distances $( \pm 20 \mathrm{~m})$ the radial wind speeds at each $x$ location (lateral displacement distance from a direct transect to the wind turbine) and $z$ height (where $z$ is defined from the elevation of the wind turbine hub height) are retrieved for each $10 \mathrm{~min}$ period. Then the vertical plane of radial velocities is discretized into $20 \mathrm{~m}$ horizontal planes and a mean radial velocity is computed for each $20 \mathrm{~m}$ plane (see Fig. 6). Anomalies from that "background" profile are then interpolated using cubic spline interpolation and used in the wake centre line identification. The location of the wake centre is determined using the maximum velocity deficit anomaly for each height starting its search at the expected location (WTHH). The location is refined by moving from that location, horizontally replacing the wake centre if the new grid cell velocity deficit is greater than the previous maximum velocity deficit value. Once locations have been checked in each $20 \mathrm{~m}$ horizontal plane, the algorithm moves to the next vertical plane and checks that, searching for the maximum velocity deficit value. The algorithm assumes that the wake has moved further downstream than the immediate rotor plane after the double-bell wake shape is expanded into a near Gaussian shape (Barthelmie et al., 2003) and hence that there is a well-defined centre.

To aid in understanding the wake detection algorithm the arc scan-derived radial velocities at the various elevation angles along with the VAD scan for an example 10 min period are given in Fig. 5. As shown, the wind turbine wake is clearly evident to and beyond distances of $4.5 \mathrm{D}$ from the 


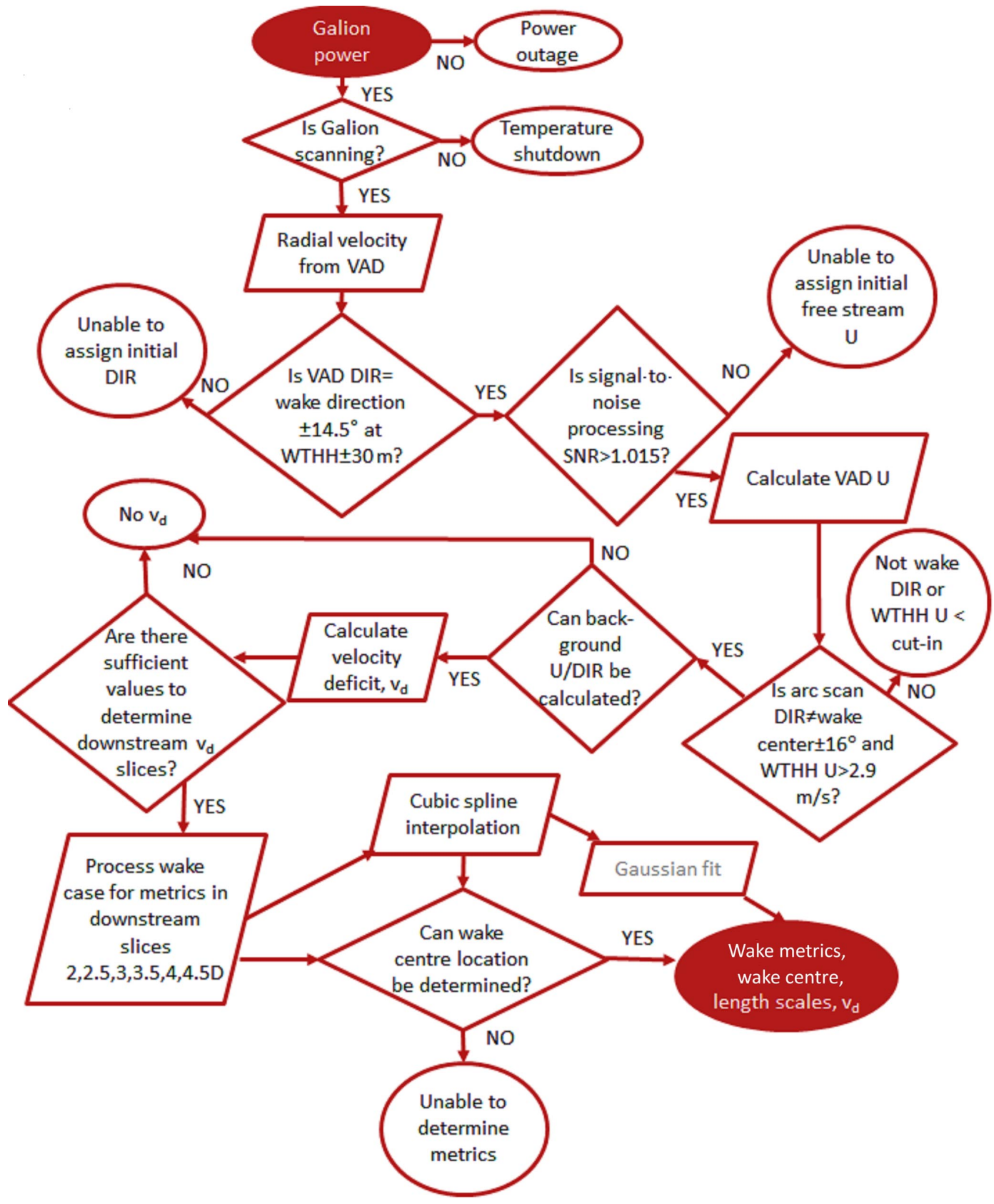

Figure 4. Flow chart outlining the automated wake processing of the Doppler lidar data for wake detection and characterization. The following abbreviations are used: DIR is direction, U is wind speed, VAD DIR is direction retrieved from VAD scans and arc scan DIR is direction retrieved from arc scans. The Gaussian fit is not used here and hence is shown in grey.

turbine in the arc scans with elevation angles 12 to $21^{\circ}$ as reduced radial wind speeds. Also shown are the radial wind speeds from the multiple VAD scans (Fig. 51) that are used to provide an initial wind speed and direction for a height equal to approximately the WTHH that is used as an initial estimate of the likely presence of a wake in the scanned volume and thus to start the processing. The inflow conditions as reported in the upper right panel of Fig. 5 d indicate the initial estimate of inflow or background wind speed upstream of the wind turbine as determined from the arc scans. Figures 5-7 also illustrate the need for normalization of the flow field on each plane to generate anomaly fields (where the background flow field is discretized in the vertical) for automated detection of the wake location. As shown in Fig. 6, the variation in raw radial velocities across the $x-z$ planes at the various downstream distances is dominated by variability induced by the topography. Specific to this example, there is clear evidence of weak upslope flow at low heights above the ground, 
overlain by flow towards the lidar aloft. Thus, although a wind turbine wake is evident, it is difficult to identify unambiguously because other local minima of equal (or greater) magnitude are present due to other mechanisms. The complexity of this flow, and the deviation from typical logarithmic profiles, is also evident from the mean background profiles shown in the middle panels. Once the anomaly fields are generated by subtracting the mean background line of sight flow profiles $(\operatorname{LoS}(z))$ at each downstream distance (i.e. each plane), the wind turbine wake centre is considerably more apparent and can be correctly identified and tracked by the automated algorithm (see Figs. 6 and 7).

\section{Results}

\subsection{Meteorological conditions during the experiment}

The Perdigão region was selected for the field experiment in part due to the presence of two ridges of approximately equal height but also for the prevailing bimodal wind direction, which means that the flow is frequently oriented perpendicular to the ridges (northeasterly or southwesterly). This flow pattern is also observed during the measurement period (Fig. 8). Higher wind speeds are observed during March and April, but the high frequency of northeasterly winds during April meant that relatively few wakes could be observed, despite the prevalence of wind turbine operating wind speeds (cut-in wind speed $\sim 3 \mathrm{~ms}^{-1}$ at WTHH). During May and June, wind speeds are consistently lower but still mainly above cut-in (Fig. 8), and the frequency of winds from the southwest increased, providing a higher number of wake situations that are detected by the Galion lidar.

In the absence of other alternatives, the stability classification and turbulence intensity from Tower 20 are used as an indicator of inflow conditions to the wind turbine. The TI at approximately WTHH is most commonly between 0.1 and 0.2 for all wind directions. The overall median is 0.13 (25th percentile is $0.09,75$ th percentile is 0.21 and mean is 0.17 ). The exception is northeasterly directions (from 50$70^{\circ} \mathrm{N}$ ) when flow comes across the valley to the sensor; TI is generally lower, with no observations above 0.3 and a large fraction below 0.1 (Fig. 9). For the wake directions used here $\left(209-241^{\circ}\right)$, the high level of TI implies that wakes will generally recover rapidly (at short downwind distances) and may be strongly temporally varying. The stability classification identifies very few observations $(<5 \%)$ as being close to near neutral $(-0.08<z / L<0.08)$, with the majority of observations split between the stable (48\%) and unstable classes $(47 \%)$ and with little directional dependence in the frequency of these classes (Fig. 9). Instead, atmospheric conditions show a strong and expected diurnal cycle for a land site (Stull, 1988), with both the number of unstable conditions and the turbulence intensity increasing during the daylight hours (Fig. 10). There is also clear association of much lower turbulence intensity with stable conditions overnight. The diurnal pattern of mean wind speeds is more complex, with a maximum in the early morning around 06:00 UTC (before sunrise at 07:52 UTC in January to 06:02 UTC in June), which might indicate the presence of a nocturnal jet and minimum values in the mid-morning around 10:00 UTC. This implies that the flow is impacted by both the valley and larger-scale synoptic systems and that complex wake behaviour is to be anticipated.

\subsection{Data processing methodology and data availability}

There were very few power or instrument issues during the measurement period of mid-January to end of June, leading to $92 \%$ availability of the scanning Doppler lidar instrument. Electrical power was supplied specifically for the experiment, and most instruments including the Cornell University scanning Doppler lidar were placed on the temporary power grid; part of the availability reduction arose from a faulty fuse in an extension line. Before this was corrected, during March, about $280 \mathrm{~h}$ of potential scan time were lost due to power issues, but only about $35 \mathrm{~h}$ were lost in April. As temperatures increased, the scanning Doppler lidar started to experience thermally induced automatic instrument shutdown during the afternoons when ambient temperatures exceeded $30^{\circ} \mathrm{C}$ and wind speeds in the valley were very low. During May there were five individual shutdown events, accounting for $54 \mathrm{~h}$ of missing scans in total. During June, afternoon shutdowns were routine, occurring on more than half of days between the times of 10:00-20:00 (UTC) for an average of $7 \mathrm{~h}$ each. However, the instrument automatically restarted once its internal temperature dropped below $40^{\circ} \mathrm{C}$, and this provided for excellent data coverage and a database of 19384 complete scans, each covering a 10 min period.

An automated processing algorithm is necessary for removing subjectivity in wake characterization and hence aid reproducibility. The algorithm developed here is summarized in Fig. 4, and the results of the pre-screening for potential wake cases are summarized in Fig. 11. The requirement for a sufficient number of points in the VAD scan to calculate an initial wind direction (and wind speeds at WTHH sufficient for wake generation) removed very few cases (eight) from further consideration. A large number of $10 \mathrm{~min}$ periods (15 894) are excluded from consideration as being potential wake cases because the wind direction as determined by the VAD scans falls outside the $209-241^{\circ}$ direction range (labelled DIR). This is consistent with observations at Tower 20 that indicate a very high prevalence of northeasterly flow (Fig. 8). A small number of possible cases (484) are identified as potential wake cases in data from the VAD scans but excluded from further consideration because the arc scans used to infer inflow wind speed and wind direction at the wind turbine report too few observations at that range from the lidar with a sufficient SNR to merit inclusion in estimating the inflow wind speed (labelled INFLOW). A few fur- 


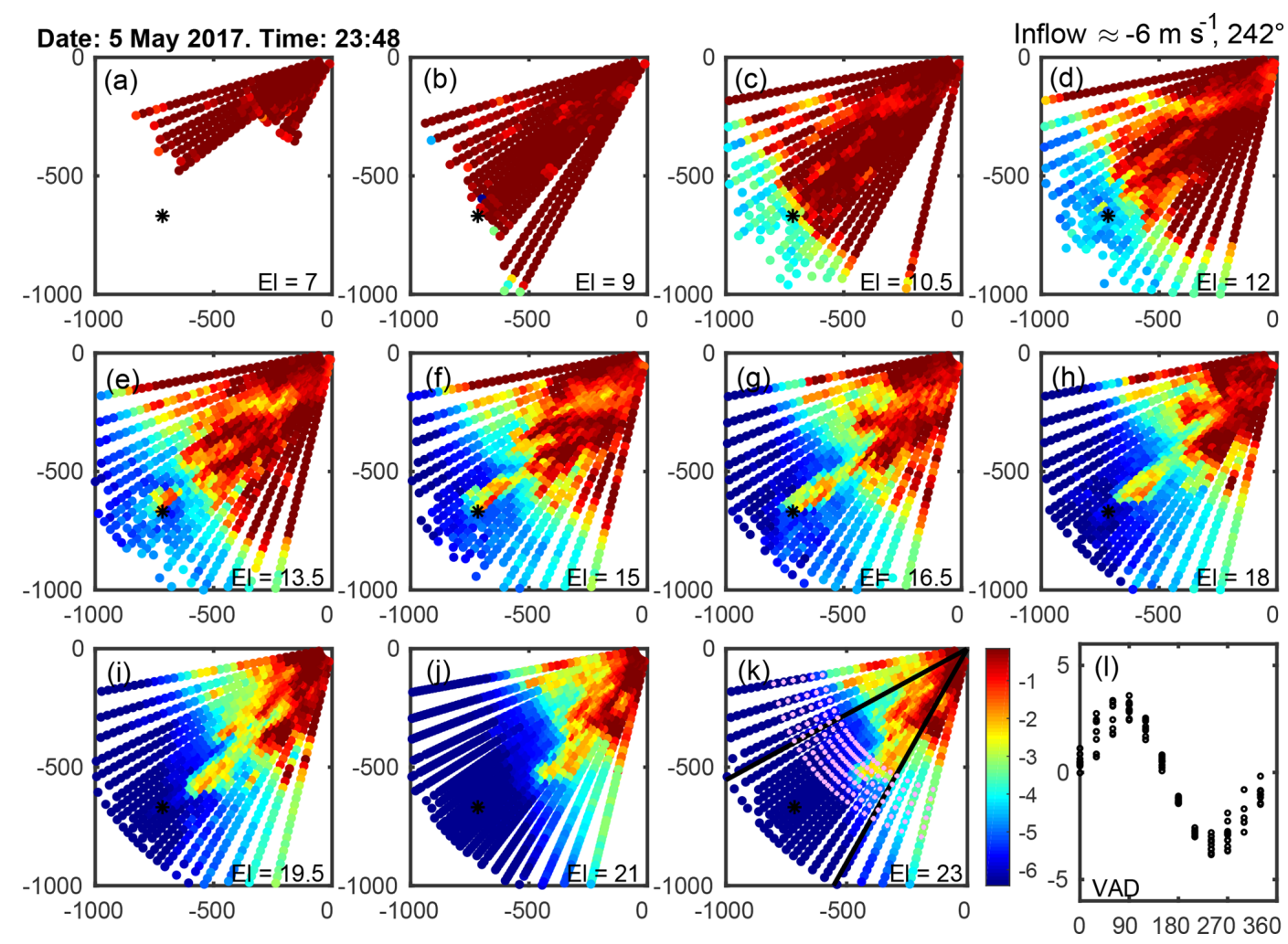

Figure 5. Example of arc scans from 5 May 2017 at 23:48 (UTC). During this 10 min period the sonic anemometer at $78 \mathrm{~m}$ a.g.1. on Tower 20 indicated a wind speed of $5.9 \mathrm{~ms}^{-1}$ and a wind direction of $252^{\circ}$, stable stratification with $z / L=2.27$, and TI $=0.05$. Data from the VAD scans (l) indicated a wind direction of $\sim 240^{\circ}$. Conditions upstream of the wind turbine as characterized by the arc scans are $6.0 \mathrm{~ms}{ }^{-1}$ and $242^{\circ}$. Each panel is $1000 \mathrm{~m}$ by $1000 \mathrm{~m}$, with the Galion located at $(0,0)$, and depicts line-of-sight (radial) wind speeds from each elevation angle: $7,9,10.5,12,13.5,15,16.5,18,19.5,21$ and $23^{\circ}$. The wind turbine location is shown by the black $*$, and panel (k) shows the location of the slices used in the wake characteristic quantification, shown as the magenta arcs at 2, 2.5, 3, 3.5, 4 and $4.5 \mathrm{D}$ downstream of the wind turbine, as well as the wake directions $209-241^{\circ}$, shown by the thick black lines.

ther cases are excluded because the inflow wind speed derived from the arc scans is below wind turbine cut-in wind speed $\left(U<3 \mathrm{~ms}^{-1} ; 1027\right)$. These pre-screening selection criteria reduce the number of observations, leaving 1971 cases (10.2\% of the original scans) that are processed to derive quantitative estimates of the wake position (and characteristics). Naturally the criteria applied are highly selective, but the purpose here is to identify cases from which quantifiable wake characteristics can be determined.

\subsection{Evaluation of the wake centre line detection}

Development of objective methods with which to evaluate the wake detection algorithm is challenging. To evaluate the performance of the automated detection algorithm an assumption is made that no wake cases are missed, which is based mainly on the practical consideration that wind speed and directions selected include all scans where the wind turbine could be operating and where the wake can reasonably be tracked for up to $4.5 \mathrm{D}$ (Fig. 7f). Of the 1971 potential wake cases, only one is rejected by the automated algorithm being unable to locate a wake centre location at $2.5 \mathrm{D}$; surprisingly this number did not increase above 3 with increasing distance from the wind turbine. Subjective inspection of the wake cases indicated that they can be classified into four possible scenarios: (A) a straightforward wake type with a clear and correctly defined centre, (B) a type where the wake centre is split but the wake centre is broadly identified by the algorithm, (C) a type where the algorithm mis-specifies the wake centre location, and (D) a type where the algorithm is unable to locate a wake but subjective inspection could not do so either (Table 2). Figure 12 shows illustrative examples of the four wake types on planes $2.5 \mathrm{D}$ from the wind turbine selected from a $24 \mathrm{~h}$ period during 3-4 May 2017. These serve to illustrate why the objective process is challenging. For the A type, the wake is shown as a central area where there is positive radial velocity with lower or negative velocities around it. Recall that in all the cases presented, the wind direction is southwesterly, and so the flow is towards the lidar (i.e. negative radial velocities) and thus the wake will appear as a positive anomaly. These 519 events comprise $46 \%$ of all potential wake cases. Only a relatively small number of cases 


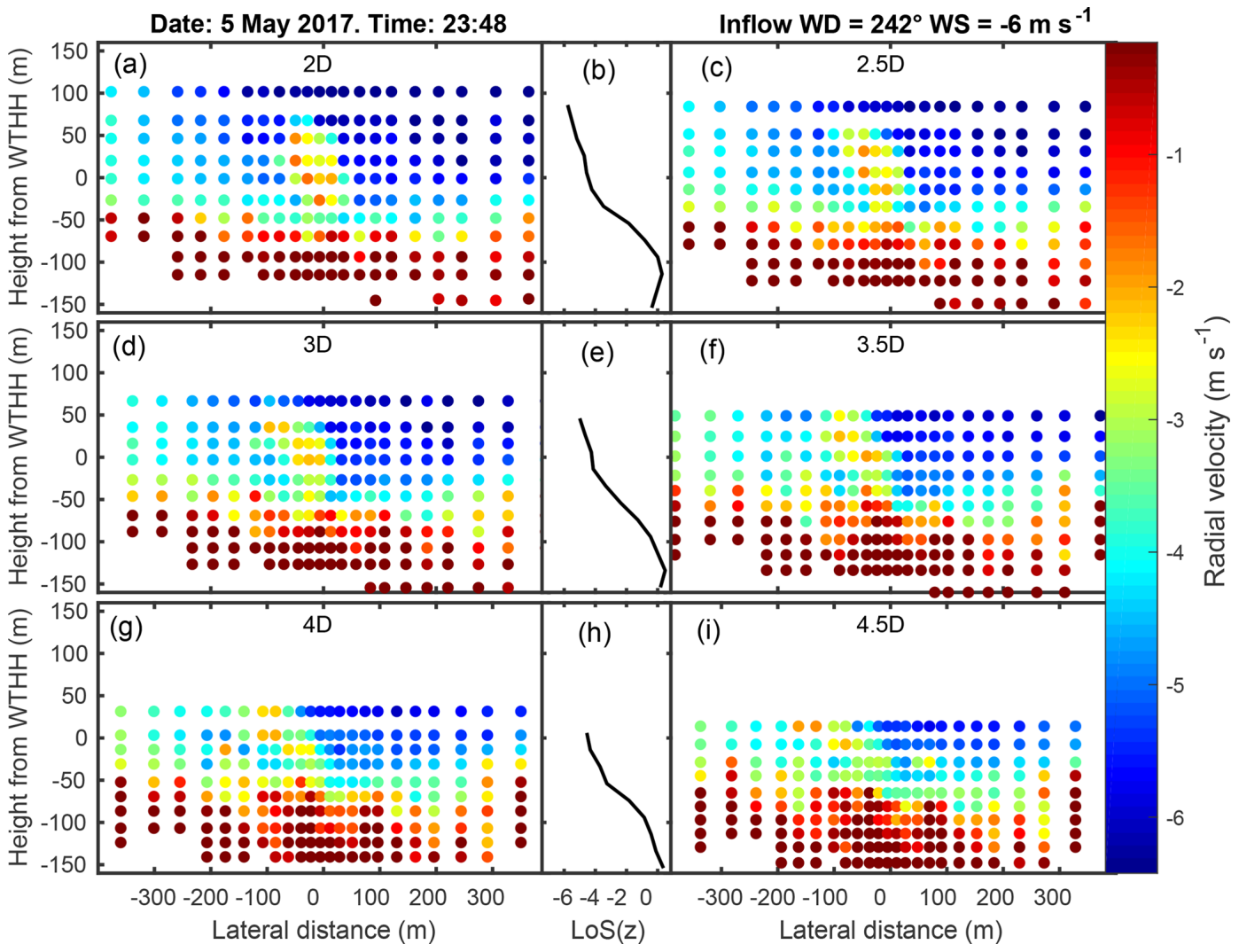

Figure 6. Example of raw radial wind speeds on planes at the six downstream distances, 2, 2.5, 3, 3.5, 4 and $4.5 \mathrm{D}$, from the arc scans on 5 May 2017 at 23:48 (UTC; shown in Fig. 5). In (b, e, h), the mean background radial wind speed profile (LoS $(z))$ is shown at 2.5, 3.5 and $4.5 \mathrm{D}$. A lateral distance of 0 (on the $x$ axis) indicates a direct line to the wind turbine (i.e. a direction of $227^{\circ}$ ). The heights on the vertical axis have been normalized to be 0 at the WTHH.

(58) are subjectively identified as exhibiting a clear wake, but that location is incorrect in the tracking algorithm at $2.5 \mathrm{D}$ (i.e. category C). Not all wind turbine wakes are manifest as a single positive velocity anomaly. In type B, the wake area is present as multiple lobes and does not have an obvious wake centre; $16 \%$ of the 1971 potential wake cases exhibit a split wake of this type (type B), but the algorithm correctly identifies parts of the wake. In $33 \%$ of potential wake cases no wake is subjectively observed, although conditions would predict they should be present. There are several variants of type D. The most common is that it is not possible to distinguish a centre of velocity deficit from the complexity of the background flow (type D; Fig. 12d) sometimes because what could potentially be the wake is split. However, in most of these, there are other areas of much lower velocity present in the scan. The example of a D type shown in Fig. 12d is very typical of the flow complexity, with weak upslope or downslope flow to the right or left of the centre line to the wind turbine (shown as lateral distance of 0 ). This flow pattern persisted for many consecutive time periods and thus appears to represent microscale topographic forcing of the flow (see slope variability in Fig. 1). Naturally, not all $D$ wake types are reflective of flow complexity. There are also a few where the velocity deficit is not present; use of SCADA data might remove some of these, as it is possible that the wind turbine was not operating during all 10 min periods.

The diversity of possible outcomes under conditions that should be conducive to wake generation (Fig. 4) also indicates how the process of developing a wake processing algorithm can be challenged by flow complexity. While data from both Tower 20 and the scanning Doppler lidar indicate that flow from the southwest and a wake can clearly be identified for at least $4.5 \mathrm{D}$ downstream of the wind turbine for the higher elevation scans, under the frequently occurring condition of recirculation flow in the valley (Menke et al., 2019) (with radial flow away from the lidar while flow on the ridge is towards it), wake velocities blend with the local flow and cannot be distinguished, even if the wake is present. To assist understanding of the reasons why different wake forms (cases) wakes develop in different ways, the external conditions (stability, wind speed, wind direction and turbulence intensity) associated with each type are investigated (Table 2 and Fig. 13). For type A, the majority of cases occur in stable conditions (median $z / L=0.22$ ), and with a similar TI $(0.10)$ to the average $(0.11)$, the mean wind direction is also very close to the direct centre line to the wind turbine; other- 

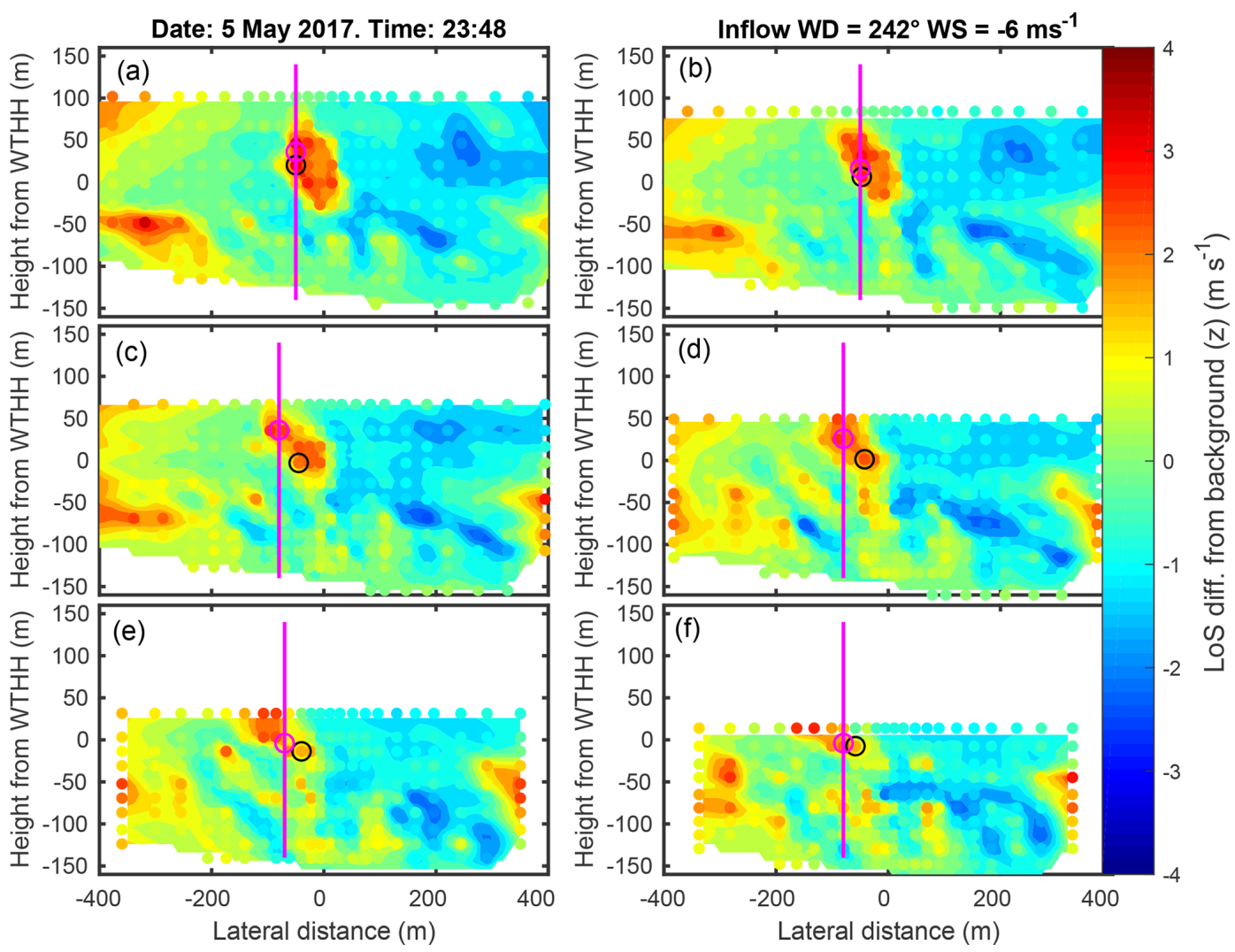

Figure 7. Example of radial wind speed anomalies at the six downstream distances, 2, 2.5, 3, 3.5, 4 and $4.5 \mathrm{D}$, from the arc scans on 5 May 2017 at 23:48 (UTC; the data used to construct the anomalies are as shown in Fig. 6). Points indicate the measurement locations, while the background shading is a cubic spline interpolation of the anomalies (shown only to aid visual interpretation). The black open circle denotes the first guess location of the wake centre line from the previous "slice" or in the first panel from the inflow conditions. The magenta circle shows the centre location as identified by the tracking algorithm. To aid in identifying the location of this circle a vertical line is shown that the bisects this location.

Table 2. External conditions from $78 \mathrm{~m}$ height at Tower 20 calculated for subjective classification of wake types. There are 1971 wake cases in total, with 1120 having meteorological data available.

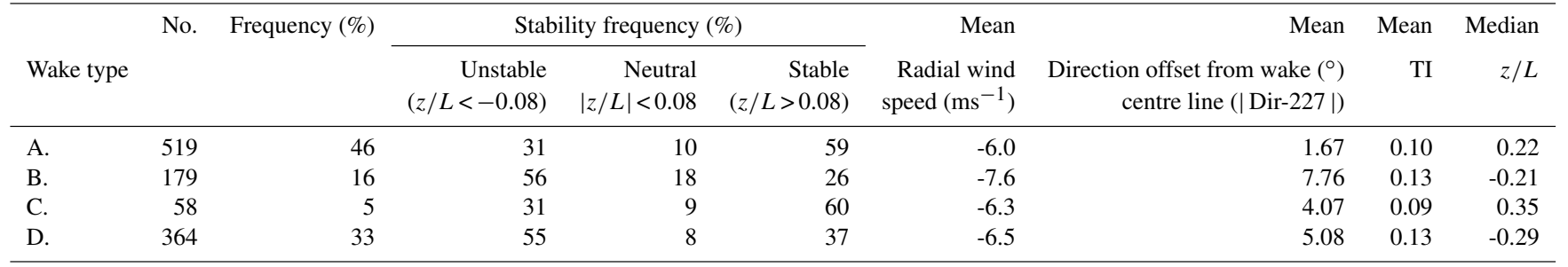

The wake types are as follows: A is clear wake centre, with wake location correctly identified by algorithm, B is split wake with no well-defined centre or multiple centres, with location being correctly identified by algorithm, $\mathrm{C}$ is clear wake centre, with location being incorrectly identified by automated algorithm, and $\mathrm{D}$ means that it is not possible to identify a wake centre subjectively or automated algorithm.

wise there is little to distinguish external conditions from the other cases in terms of the radial wind speed $\left(-6.7 \mathrm{~ms}^{-1}\right)$. External conditions for type $\mathrm{C}$ are similar to type A but exhibit a greater frequency of highly stable conditions (me$\operatorname{dian} z / L=0.35)$ and a larger average directional offset from the direct azimuth angle to the wind turbine $\left(4.1^{\circ}\right)$. Split or multiple wake centre cases (type B) are associated with the highest radial wind speeds at the wind turbine $\left(-7.5 \mathrm{~ms}^{-1}\right)$, the largest average directional offset from $227^{\circ}\left(7.8^{\circ}\right)$, and are more likely to occur under unstable conditions (median $z / L=-0.21)$ and high TI (mean $=0.13)$. Type $\mathrm{D}$ cases are observed in atmospheric conditions that are similar to those that prevail during type $\mathrm{B}$ cases. 
(a)
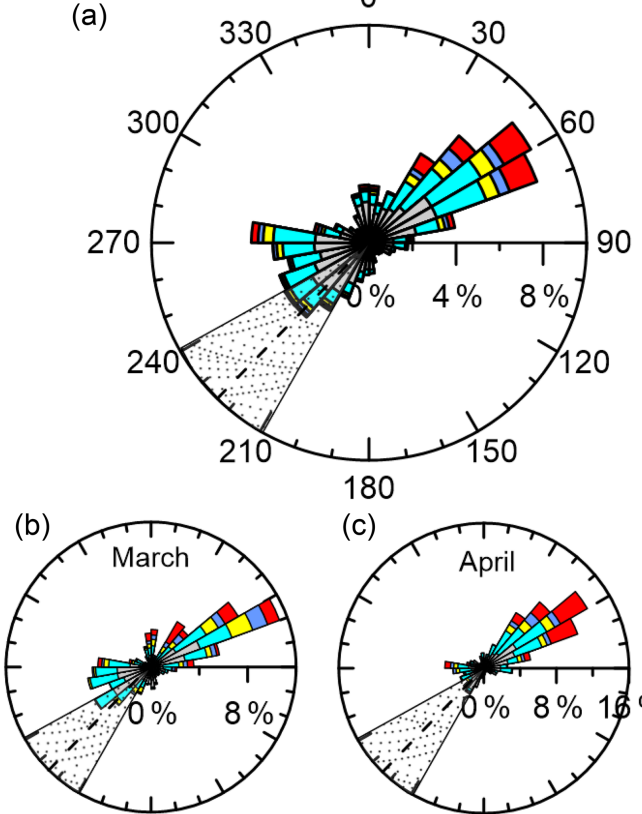

(d)

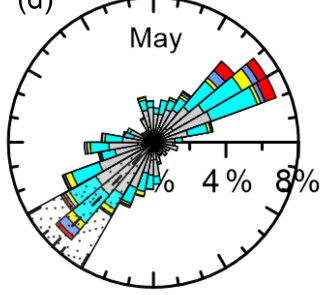

(c)

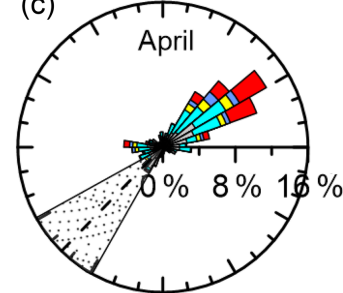

(e)

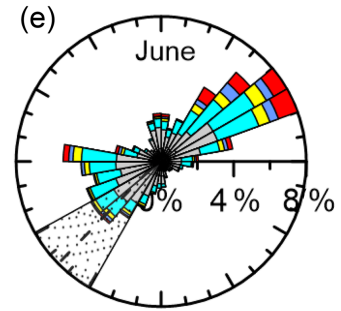

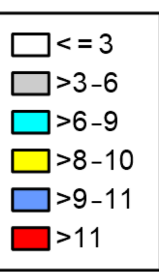

Figure 8. Panel (a): wind rose from $78 \mathrm{~m}$ height at Tower 20 (location shown Fig. 1) for all 10 min periods during March-June 2017. Coloured bars show the wind speed (in ms ${ }^{-1}$ ). Panels (b-e): wind rose for each month. The shaded grey area shows the primary wake directions $\left(209-241^{\circ}\right)$, with the wake centre line direction of $227^{\circ}$ being marked with the black dashed line.

\subsection{Dependence of wake centre location on prevailing external conditions}

The 519 A type wakes when sonic anemometer data available from Tower 20 are conditionally sampled by wind speed and direction, stability (hour of the day), and turbulence intensity to examine the mean wake propagation characteristics and their dependence on the prevailing meteorology. At $2 D$, the ensemble mean height of the wake centre is $+11.1 \mathrm{~m}$ relative to the WTHH (i.e. as if the wake propagated on a horizontal line from the wind turbine centre), but subsequently it moves downslope such that the average height at $4.5 \mathrm{D}$ downstream it is $-36 \mathrm{~m}$, or just under $0.5 \mathrm{D}$ below the WTHH (Fig. 14). Although the standard deviation of the wake centre height at each downstream distance is large, the tendency of the wake centre to initially loft and then move down the slope, broadly following the grade of the terrain, is clear. It is worth noting that the wake also expands as it moves downstream. Using Eq. (11), the mean wake width expands from 82 to $107 \mathrm{~m}$
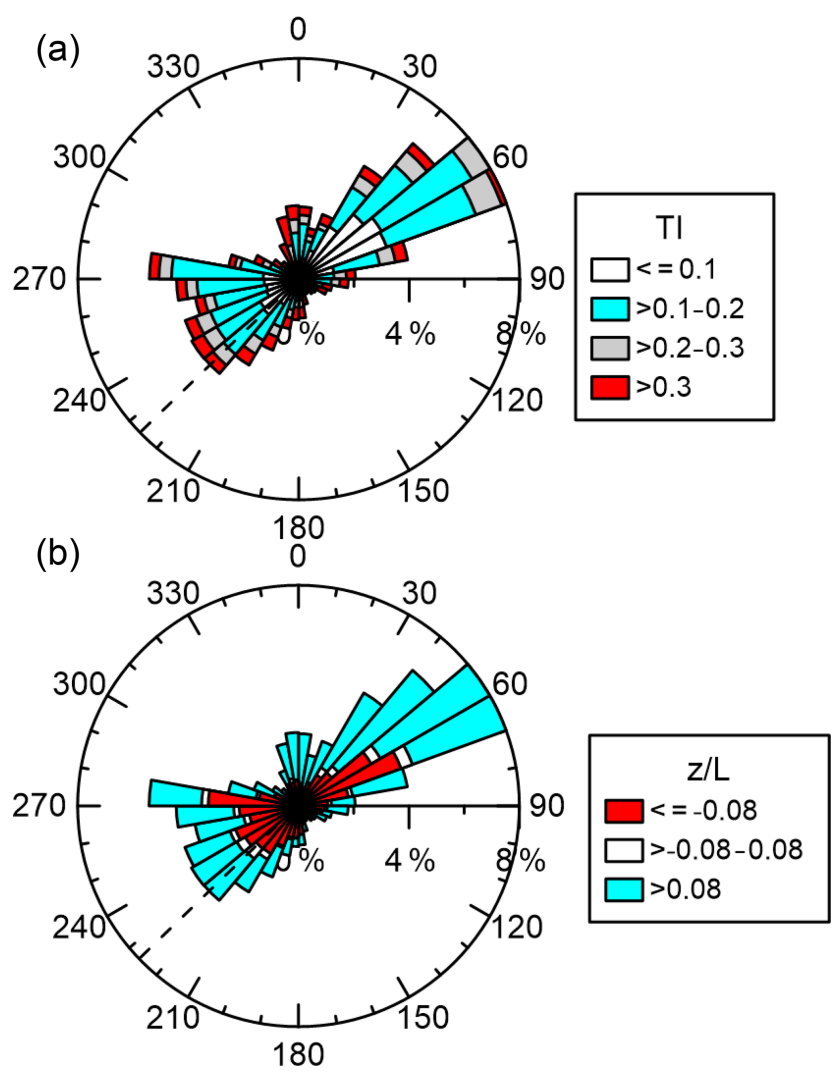

Figure 9. Top: turbulence intensity rose from $78 \mathrm{~m}$ height at Tower 20 (location shown Fig. 1) for March-June 2017. Coloured bars show the turbulence intensity defined from Eq. (12). Bottom: atmospheric stability rose from $78 \mathrm{~m}$ height at Tower 20 (location shown Fig. 1) for March-June 2018. Coloured bars show the value of $z / L$ ( $L$ is defined from Eq. 4), where white is near neutral, red is unstable and cyan is stable. The wake centre line direction of $227^{\circ}$ is marked with the black dashed line.

after $2 D$ and to $137 \mathrm{~m}$ after $4.5 \mathrm{D}$ (Fig. 14). Although the tendency is for the whole wake to remain above the inner layer (discussed in Sect. 1.2), the lower edge of the wake is within $12 \mathrm{~m}$ of the inner-layer height (and the uncertainty on both heights) means that it is plausible that the wake volume interacts with the inner layer, especially in unstable conditions.

The vertical location of the wake centre exhibits strong diurnal variability (as a proxy for atmospheric stability) with lower wake centres during the day when conditions are most unstable and highest overnight when conditions are stable (indicated in Fig. 15 using the median value of $z / L$ from $78 \mathrm{~m}$ height at Tower 20 from the same date/time as the wake cases). In most hours the wake centre is initially lofted, likely directed by flow over the crest, but then descends and broadly follows the slope. At $2 D$ the mean wake centre is above WTHH during the night hours but has a mean value of $-8 \mathrm{~m}$ (relative to WTHH) at 08:00 UTC. Thus, there is a tendency for the wake centre to be higher in stable than unstable con- 


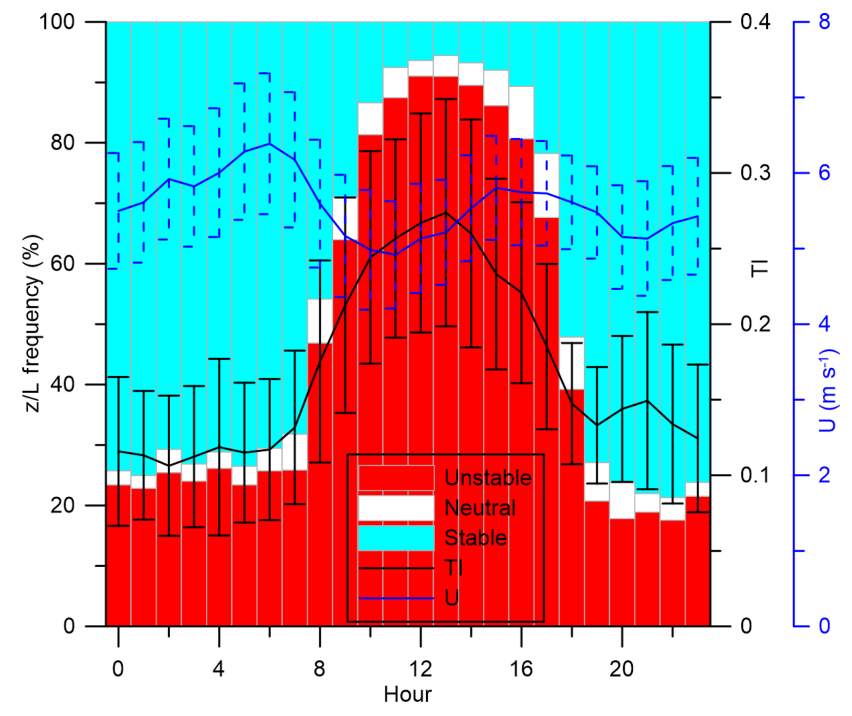

Figure 10. Diurnal variability of meteorological variables from measurements at $78 \mathrm{~m}$ at Tower 20 for the whole data set (March to June 2017). The frequency of atmospheric stability classes $(z / L<-0.08$ is unstable, $z / L<|0.08|$ is neutral and $z / L>0.08$ ia stable; bars), wind speed ( $U$; blue line with dashed error bars showing $0.25 *$ standard deviation) and turbulence intensity (TI; black line with error bars showing $0.25 *$ standard deviation).

ditions (Fig. 16). The daytime hours of 09:00 to 17:00 UTC are largely associated with unstable conditions. During these hours of the day, the mean wake centre is slightly above the equivalent WTHH $(+3.5 \mathrm{~m})$ at a downstream distance of $2 \mathrm{D}$ to an average of $-50 \mathrm{~m}$ by a distance of $4.5 \mathrm{D}$ (Figs. 15 and 16). In stable conditions that prevail during 18:00 to 07:00 UTC, the mean wake centre is an average of $+13.5 \mathrm{~m}$ from WTHH at $2 \mathrm{D}$ and $-33 \mathrm{~m}$ at $4.5 \mathrm{D}$. Most stable hours have wake centre trajectories that are higher than the majority of those in unstable hours (see the groupings of stable wake centre trajectories in blue colours vs the unstable wake centre trajectories in red colours in Fig. 16). Despite this clear signal, there is also variability both in the grouping of individual hours into different stability classes and the height of the wake centre trajectory by stability. For the most extreme case of lofting, in the hour 21:00 UTC (marked $L$ ) conditions are stable and the average of all values for the wake centre is $+27 \mathrm{~m}$ at $2 \mathrm{D}$ downstream but then descends to $-38 \mathrm{~m}$ by $4.5 \mathrm{D}$. In contrast, at $08: 00 \mathrm{UTC}$, an hour that is defined as near neutral (marked 8), and at 13:00 UTC, an hour that is very unstable (marked $D$ ), the wake centre drops below $-40 \mathrm{~m}$ after $3 \mathrm{D}$ downstream. The behaviour of wakes is clearly very complex, but despite a large amount of scatter, there is a consistent relationship between the value of $z / L$ and the wake centre height for each downstream distance, with wake centres in stable conditions being higher (Figs. 15 and 16).

Naturally the hour of the day is an imperfect surrogate for stability due to the complexity of the relationships between

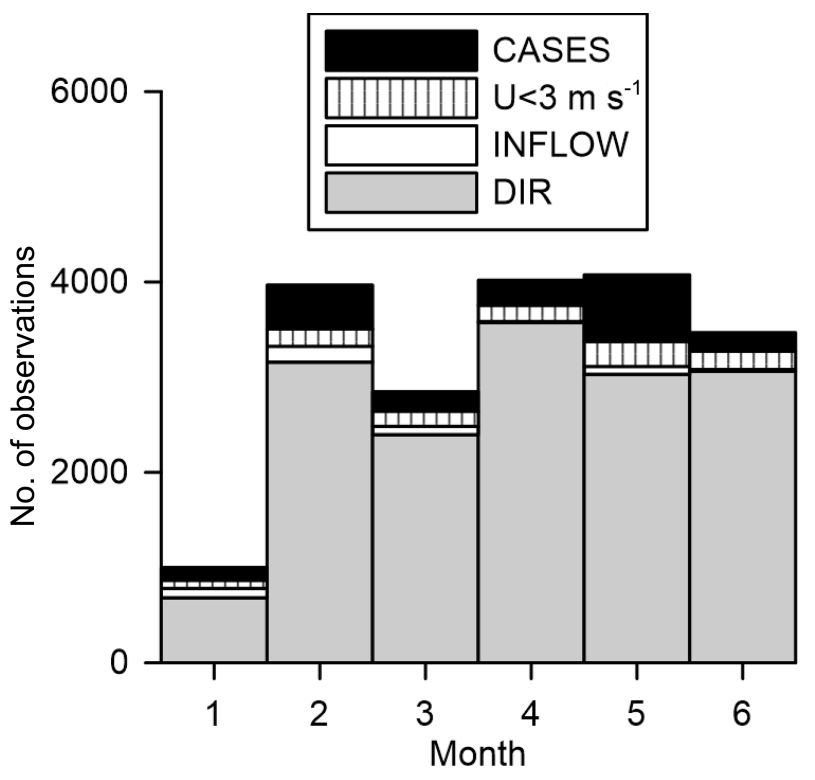

Figure 11. Results of the wake case selection pre-processing (flow chart shown in Fig. 4) by calendar month (1 is January 2017, 2 is February 2017 and so on). The total column heights indicate the number of $10 \mathrm{~min}$ periods for which data are available in each month. DIR indicates the number of scans excluded from consideration because the VAD-derived wind direction was not 210 or $240^{\circ}$. INFLOW indicates the number of scans filtered out by having insufficient observations at or slightly beyond the wind turbine to determine the inflow. $U<3 \mathrm{~ms}^{-1}$ indicates scans filtered by having wind speed at hub height lower than the wind turbine cut-in wind speed at the turbine location. CASES denotes the $10 \mathrm{~min}$ periods that are identified as potential wake cases that meet the criteria for quantitative processing.

wind speed, turbulence intensity and stability, and their impact on wake generation and behaviour. The velocity deficit is large for low to moderate inflow wind speeds (Barthelmie et al., 2013), but the expansion, coherence and meandering of wakes is driven by the external flow impacted by stability, turbulence and the downstream flow characteristics. Furthermore although in the whole data set, the locally determined $L$ and TI are strongly linked to the hour of the day (Fig. 10), there is a high degree of spatial variability in near-surface stability, and estimates based on similarity theory may not be fully valid for heights relevant to the wake, particularly given variability in the larger-scale (synoptic) flow and the presence of thermo-topographic flows.

Wake centre location is strongly linked to inflow wind speed as estimated from data from Tower 20 (Fig. 17). Wake centres are higher above ground level under lower wind speeds, and their average locations are above the WTHH horizontal line (initially lofted) for all but the highest wind speeds. For higher inflow wind speeds, the mean wake centre is consistently further below WTHH. Given that the flow is perpendicular to the ridge for wind turbine wakes to be observed, the wind speed dependence of wake centre position 
(a) Type A

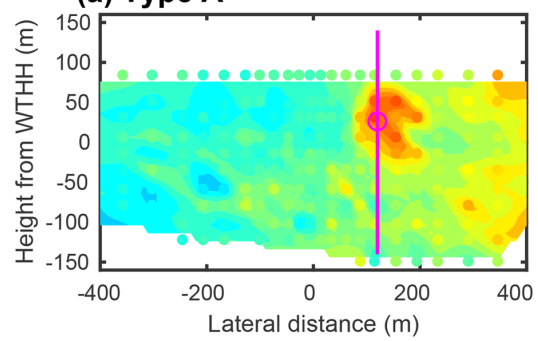

(c) Type C

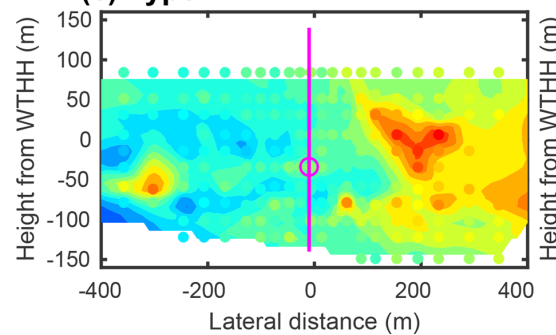

(b) Type B

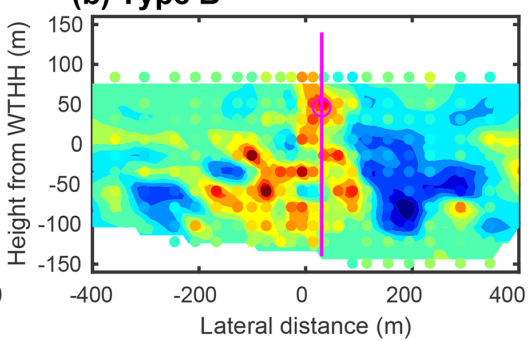

(d) Type D

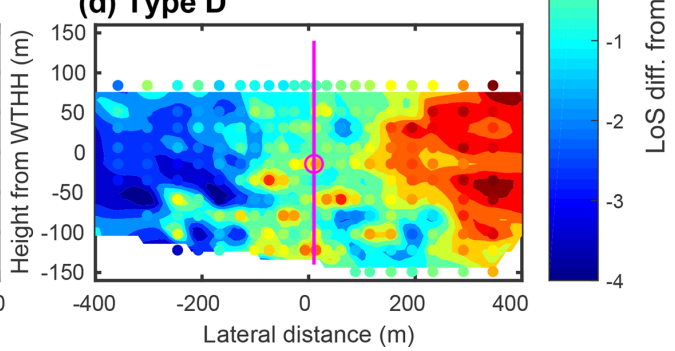

Figure 12. Representative examples of radial velocity anomalies at $2.5 \mathrm{D}$ distance from the wind turbine for the four types. The scanning Doppler lidar measurements are shown as individual points, whereas the solid colours are values interpolated by cubic spline. The results of the automated wake detection algorithm are shown as magenta circle for the wake centre. To aid visibility the location of the wake centre is extended vertically as a magenta line. The wake types are as follows: A is clear wake centre, with wake location being correctly identified by algorithm, B is split wake with no well-defined centre or multiple centres, with location being correctly identified by algorithm, $\mathrm{C}$ is clear wake centre, with location being incorrectly identified by automated algorithm, and D means that it is not possible to identify a wake centre subjectively or automated algorithm.

may reflect the likelihood that flow at/near the wake height is more/less likely to be fully attached to the underlying terrain (see discussion in Sect. 1.2 and Whiteman and Doran, 1993).

For every downstream distance, the wake centres are lower in unstable daytime conditions than in overnight stable conditions, likely due to complex covariation of wind speed and stability and the degree of coupling of flow near the WTHH to the surface conditions and flow aloft. This finding is in contrast to case studies presented in a previous study at Perdigão (Menke et al., 2018). However, the location and configuration of the Doppler lidars in the two studies is fundamentally different, and thus the wake detection in the two studies is differentially sensitive to background flow inhomogeneity. The earlier study (Menke et al., 2018) analysed data from lidars scanning in the near horizontal (i.e. at considerable height above the intervening valley and ridge slopes), whereas here data are reported from a scanning Doppler lidar configured to scan upslope towards the wind turbine. The study presented here represents a statistical assessment of 519 wake cases collected over the period January-June 2017 that track the wind turbine wake centre directly over distance of up to $4.5 \mathrm{D}$ downstream, whereas the earlier study of data based on 21 cases in the summer of 2015 also include the hill wake which is propagated over more than $15-30 \mathrm{D}$. Of the cases presented in the earlier research, 14 indicated upwards movement while 6 were propagated horizontally and 2 were propagated downwards (no information was provided regarding the distances downstream at which these vertical dis- placements were detected). There are also major differences in the stability classification applied. In this research, the stability is defined based on $z / L$ from the sonic anemometer at WTHH (wind turbine inflow), whereas Menke et al. (2018) defined stability from $3 \mathrm{~km}$ resolution simulations with the Weather Research and Forecasting model for an unspecified height.

\section{Summary and conclusions}

The behaviour and characteristics of wind turbine wakes in complex terrain are investigated using long-term measurements from scanning Doppler lidar from the Perdigão experiment in Portugal. Local meteorology (stability, wind speed, wind direction and turbulence intensity) is defined using data from $78 \mathrm{~m}$ (the wind turbine hub height) on the meteorological tower close to the wind turbine. This follows a typical diurnal cycle with the predominance of stable, low-turbulence conditions overnight and unstable, high-turbulence conditions during the day. There are very few near-neutral conditions, and the lack of a clear diurnal signal in wind speed is indicative of multiple scale impacts on the flow, including both physical and thermal forcing.

A single wind turbine is located on a hill crest in the double-ridge valley where height and length scales indicate that the height of the inner layer is $\sim 40-70 \mathrm{~m}$ and of the outer layer $230-280 \mathrm{~m}$. It can be anticipated that the down- 

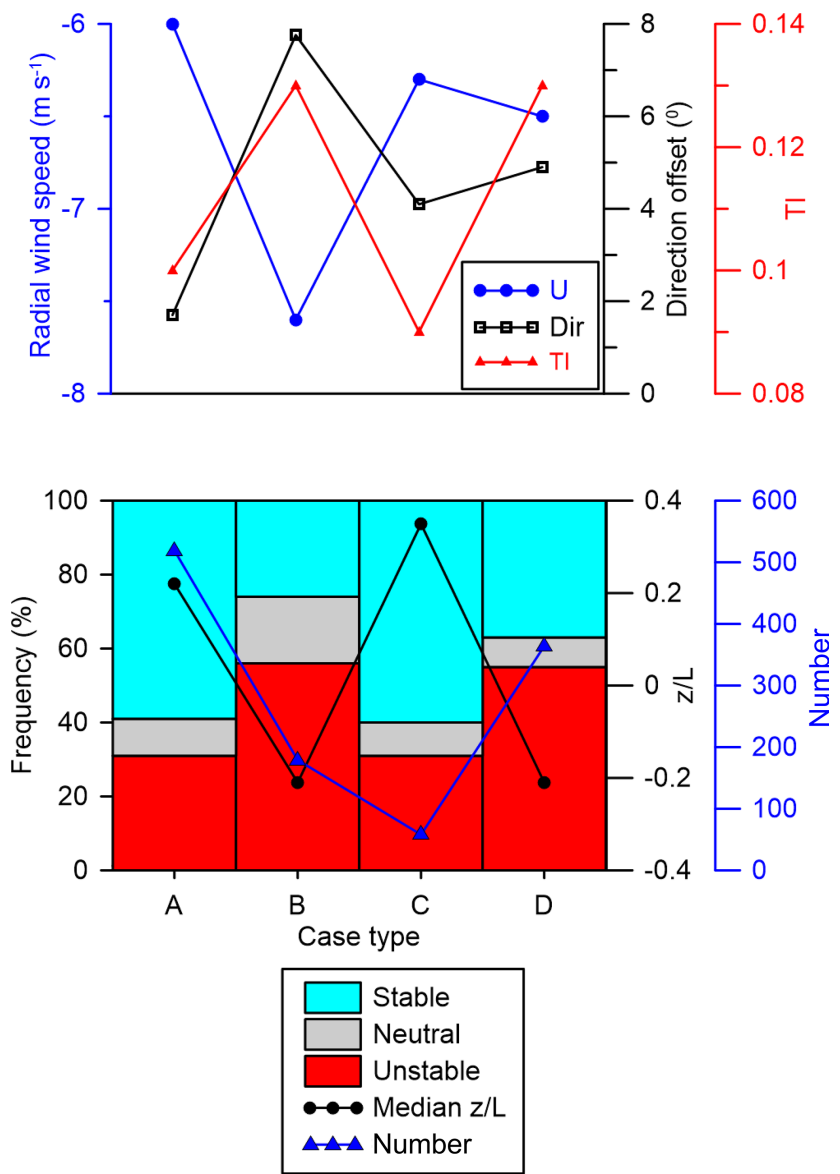

Figure 13. Mean inflow conditions and stability conditions conditionally sampled by wake type, where A is clear wake centre, with location being identified, B is split wake with no well-defined centre or multiple centres, with location being identified, $\mathrm{C}$ is clear wake centre, with location being missed, and D means that it is not possible to identify a wake centre. Stability is classified based on $z / L$ from $78 \mathrm{~m}$ height from Tower 20 , where stable $z / L>0.08$, unstable $z / L<-0.08$ and neutral $z / L<|0.08|$. Top: mean radial wind speed, turbulence intensity and direction difference from $227^{\circ}$ by wake type. Bottom: frequency of stability conditions and the median value of $z / L$ in each wake type. Lines joining the types are to aid clarity.

stream wake flow remains within the outer layer and is impacted also by turbulent stresses in the inner layer (Kaimal and Finnigan, 1994). While crest speed-up is likely to be maximum at heights below the bulk of the wind turbine wake, the interaction of the hill wake and the wind turbine wake is important.

The Doppler lidar scan geometry was designed to optimally capture data for wind turbine wakes as they move downwind of the turbine and are impacted by the flow and meteorological conditions over this complex terrain. A large data set of over 19000 scans is obtained. An objective processing method is developed and applied to identify the wake and characterize its behaviour. Here the focus is on the loca-

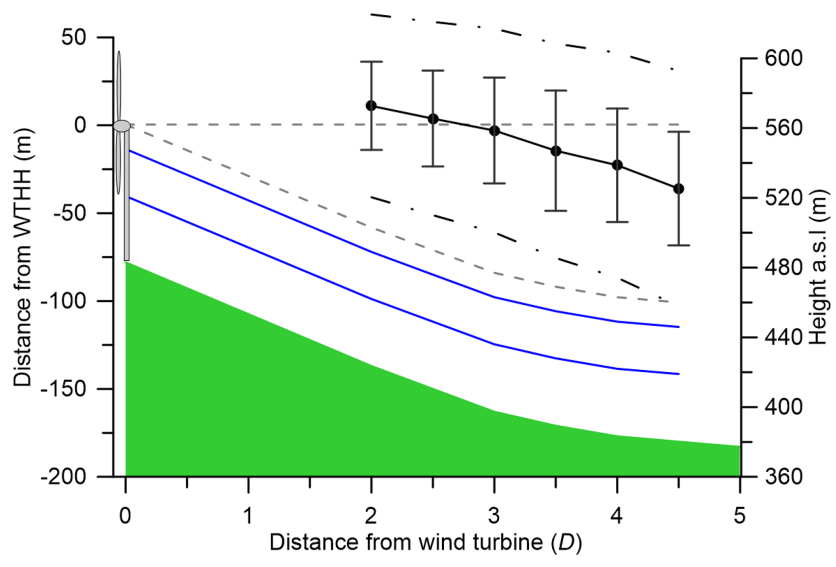

Figure 14. The mean height of the wake centre is shown with a solid black line ( \pm 1 standard deviation in solid grey lines) for distances downwind of the wind turbine at $0.5 \mathrm{D}$ intervals from 2 to $4.5 \mathrm{D}$ for A types only. The width of the wake indicated by Eq. (11) is shown as the black dashed-dotted lines. The terrain is shown in green. The grey dashed lines indicate the expected wake centre if it remained at the WTHH and if the centre purely follows the terrain. The solid blue lines indicate the range of heights for the inner layer $l$ from Table 1.

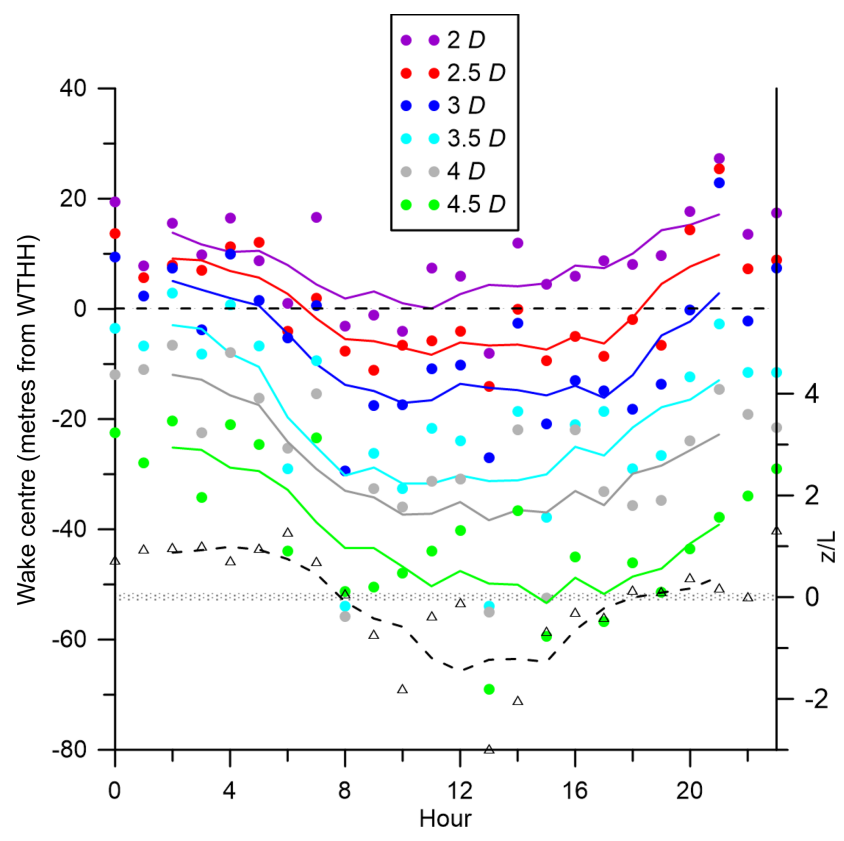

Figure 15. Mean vertical location of the wake centre by hour of the day (A type only) for different distances $(2-4.5 \mathrm{D})$ downstream from the wind turbine location. Coloured dots show the height of the centre relative to the wind turbine hub height (WTHH - the dashed line at $0 \mathrm{~m}$ ), and the lines depict a five-point running mean for each downstream distance. Also shown is the median value for $z / L$ for each hour (black line and open triangles), with near-neutral conditions being indicated by the shaded bar (right-hand axis). 


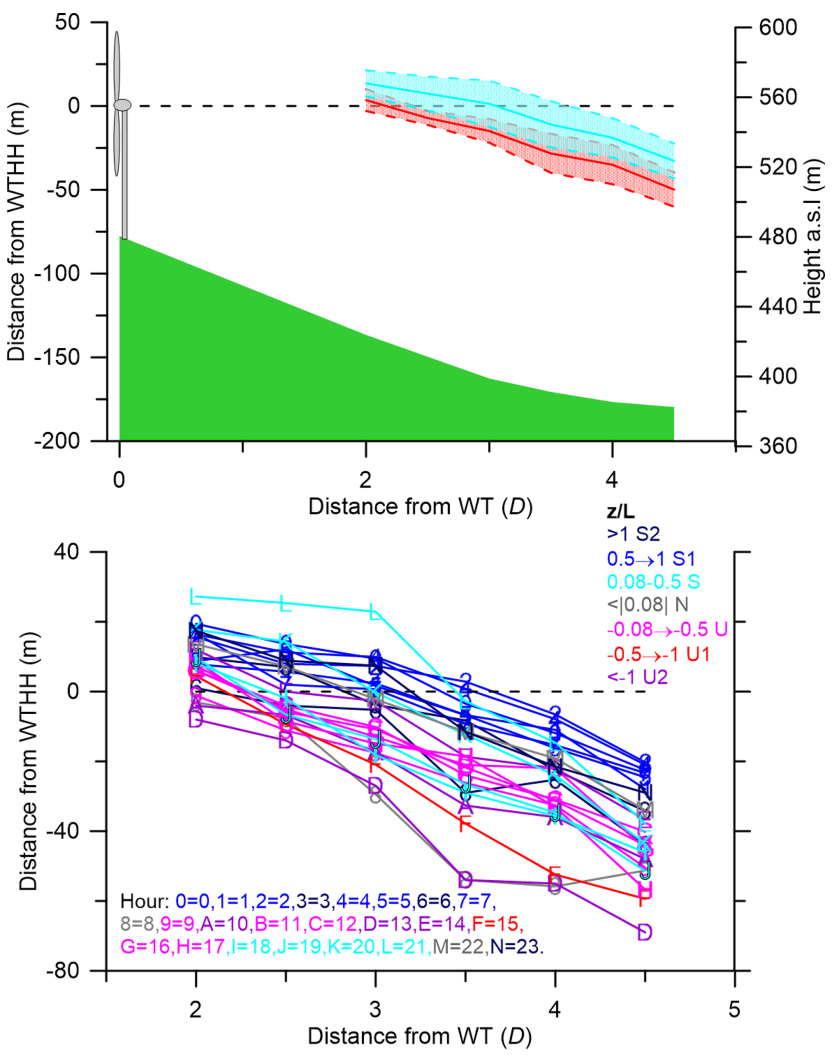

Figure 16. Top: mean vertical location ( \pm 1 standard deviation) of the wake centre by hour of the day for different distances downstream of the wind turbine location (A type only) during hours with unstable conditions (red is median value of $z / L<-0.08$ ) and stable conditions (cyan is median $z / L>0.08$ ). Bottom: same data as in the upper panel but shown by hour of the day. Wake centre locations are shown for each hour of the day (indicated by the number and letter in the inset box). Red and pink colours indicate hours typified by unstable conditions, blue colours depict hours of the day when stable conditions prevail, and the grey lines depict data from hours where conditions are frequently near neutral. The legend to the hour is given in the bottom left of the figure, where the hour shown by 0 is midnight, 1 is 01:00 UTC and so on to $N$ is 23:00 UTC. The corresponding stability colour is given in the legend in the top right. The classes are as follows: $S 2$ where $z / L>1$ is the most stable (dark blue colour), $S 1$ where $0.5<z / L<1$ is very stable (blue), $S$ where $0.08<z / L<0.5$ is stable (cyan), $N$ where $z / L<|0.08|$ is neutral (grey), $U$ where $-0.08>z / L>-0.5$ is slightly unstable (pink), $U 1$ where $-0.5>z / L>-1$ is unstable (red) and $U 2$ where $z / L<-1$ is unstable (purple).

tion of the wake centre identified by the algorithm in nearly 2000 cases when the wind speed and direction are conducive to wake development. The wake centre location is correctly identified relative to subjective detection in $62 \%$ of cases and missed in only $5 \%$ of cases. A clear wake centre is identified but is split into multiple lobes in a further $16 \%$ of cases which require more detailed investigation and analysis. The main differences in external meteorological conditions be-

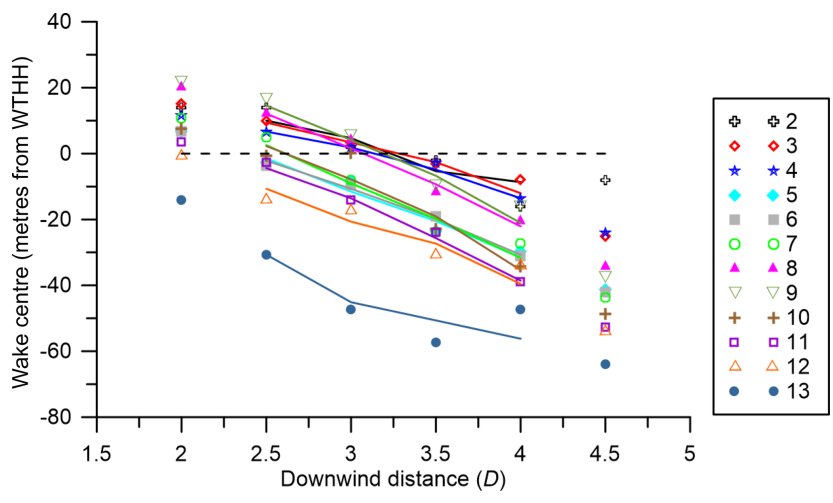

Figure 17. Mean vertical location of the wake centre conditionally sampled by inflow tower wind speed at $78 \mathrm{~m}$ height $\left(\mathrm{in} \mathrm{ms}^{-1}\right.$ ) for different distances downstream of the wind turbine location (A type only).

tween the coherent and split wakes are linked to higher wind speeds and turbulence and more unstable conditions in split wakes. The remaining $33 \%$ of cases are divided into cases where no wake can be identified - possibly because the wind turbine is not operating - and cases where the flow pattern is so complex that neither the algorithm nor a subjective approach could detect a wake signature.

Despite the complexity of the flow over the study site, the automated algorithm successfully identifies wakes when they are present, and based on tracking of over 500 clearly defined wakes, the wake is initially directed by the lofting of flow over the crest and that it remains on average higher in stable low wind speed conditions and descends most rapidly under conditions of high wind speeds. Wakes are always initial lofted except in a few cases with inflow wind speeds above $11 \mathrm{~ms}^{-1}$, which is likely from wakes following the streamlines of lofted flow over the hill crest. There is a very clear diurnal cycle with wake centres moving downslope more consistently in unstable conditions during the day and remaining at greater heights during stable conditions. There is also a consistent pattern in the location of the wake height being higher in low wind speeds, when conditions tend to be more stable or unstable. Further analysis of the wake characteristics at Perdigão will be directed towards the magnitude of the velocity deficit and the wake expansion under different meteorological conditions.

Data availability. All data analysed herein are available for download from the New European Wind Atlas data portal (2018) hosted by the University of Porto and accessible at https://perdigao.fe.up.pt (last access: 23 June 2019). Cornell Galion Scanning Lidar Data are also available at https://doi.org/10.26023/74K3-7KYB-3G03 (Barthelmie and Pryor, 2019). 
Author contributions. RJB and SCP jointly obtained the funding, designed and conducted the measurement campaign, developed and applied the data processing algorithm to analyse the data sets, and wrote the paper.

Competing interests. The authors declare that they have no conflict of interest.

Special issue statement. This article is part of the special issue "Flow in complex terrain: the Perdigão campaigns (ACP/WES/AMT inter-journal SI)". It is not associated with a conference.

Acknowledgements. We are grateful to the scientists and technicians of the Technical University of Denmark (DTU), the INEGI, the University of Porto and the National Center for Atmospheric Research for their logistical support during the Perdigão measurement campaign; the municipality of Vila Velha de Ródão; landowners who authorized installation of scientific equipment in their properties; the residents of Vale do Cobrão, Foz do Cobrão, Alvaiade and Chão das Servas; and local businesses who kindly contributed to the success of the campaign. The space for the operational centre was generously provided by Centro Sócio-Cultural e Recreativo de Alvaiade in Vila Velha de Rodão. Grateful appreciation is extended to DTU-Wind Energy for hosting Sara C. Pryor and Rebecca J. Barthelmie during their sabbatical years, particularly to Hans E. Jørgensen, Head of Meteorology and Remote Sensing, to the Danish-American Fulbright Commission and to Danmarks Nationalbank for a housing fellowship.

Financial support. This research has been supported by the National Science Foundation, Division of Atmospheric and Geospace Sciences (grant no. 1565505), and the US Department of Energy, Office of Science (grant no. DE-SC0016438).

Review statement. This paper was edited by Jose Laginha Palma and reviewed by three anonymous referees.

\section{References}

Abkar, M. and Porte-Agel, F.: Influence of the Coriolis force on the structure and evolution of wind turbine wakes, Phys. Rev. Fluids, 1, 063701, https://doi.org/10.1103/PhysRevFluids.1.063701, 2016.

Ainslie, J. F.: Calculating the flow field in the wake of wind turbines, J. Wind. Eng. Ind. Aerod., 27, 213-224, 1988.

Aitken, M. L. and Lundquist, J. K.: Utility-Scale Wind Turbine Wake Characterization Using Nacelle-Based Long-Range Scanning Lidar, J. Atmos. Ocean. Tech., 31, 1529-1539, https://doi.org/10.1175/jtech-d-13-00218.1, 2014.

Aitken, M. L., Banta, R. M., Pichugina, Y. L., and Lundquist, J. K.: Quantifying Wind Turbine Wake Characteristics from Scan- ning Remote Sensor Data, J. Atmos. Ocean. Tech., 31, 765-787, https://doi.org/10.1175/jtech-d-13-00104.1, 2014.

Banta, R. M., Pichugina, Y. L., Brewer, W. A., Lundquist, J. K., Kelley, N. D., Sandberg, S. P., Alvarez, R. J., Hardesty, R. M., and Weickmann, A. M.: 3D Volumetric Analysis of Wind Turbine Wake Properties in the Atmosphere Using HighResolution Doppler Lidar, J. Atmos. Ocean. Tech., 32, 904-914, https://doi.org/10.1175/jtech-d-14-00078.1, 2015.

Barthelmie, R. J.: The effects of atmospheric stability on coastal wind climates, Meteorol. Appl., 6, 39-47, 1998.

Barthelmie, R. J. and Jensen, L. E.: Evaluation of wind farm efficiency and wind turbine wakes at the Nysted offshore wind farm, Wind Energy, 13, 573-586, 2010.

Barthelmie, R. J. and Pryor, S. C.: Wake model evaluation using data from the Virtual Wakes Laboratory, Appl. Energy, 104, 834844, 2013.

Barthelmie, R. J. and Pryor, S. C.: The impact of wind direction yaw angle on cliff flows, Wind Energy, 21, 1254-1265, 2018.

Barthelmie, R. J. and Pryor, S. C.: Cornell Galion Scanning Lidar Data, Version 1.0. UCAR/NCAR - Earth Observing Laboratory, data set, https://doi.org/10.26023/74K3-7KYB-3G03, 2019.

Barthelmie, R. J., Folkerts, L., Ormel, F., Sanderhoff, P., Eecen, P., Stobbe, O., and Nielsen, N. M.: Offshore wind turbine wakes measured by SODAR, J. Atmos. Ocean. Tech., 30, 466-477, 2003.

Barthelmie, R. J., Larsen, G. C., Pryor, S. C., Jørgensen, H. E., Bergström, H., Schlez, W., Rados, K., Lange, B., Vølund, P., Neckelmann, S., Mogensen, S., Schepers, G., Hegberg, T., Folkerts, L., and Magnusson, M.: Efficient development of offshore windfarms (ENDOW): modelling wake and boundary layer interactions, Wind Energy, 7, 225-245, 2004.

Barthelmie, R. J., Frandsen, S. T., Nielsen, N. M., Pryor, S. C., Rethore, P. E., and Jørgensen, H. E.: Modelling and measurements of power losses and turbulence intensity in wind turbine wakes at Middelgrunden offshore wind farm, Wind Energy, 10, 217-228, 2007.

Barthelmie, R. J., Pryor, S. C., Frandsen, S. T., Hansen, K., Schepers, J. G., Rados, K., Schlez, W., Neubert, A., Jensen, L. E., and Neckelmann, S.: Quantifying the impact of wind turbine wakes on power output at offshore wind farms, J. Atmos. Ocean. Tech., 27, 1302-1317, 2010.

Barthelmie, R. J., Hansen, K. S., and Pryor, S. C.: Meteorological controls on wind turbine wakes, Proc. IEEE, 101, 1010-1019, 2013.

Barthelmie, R. J., Crippa, P., Wang, H., Smith, C. M., Krishnamurthy, R., Choukulkar, A., Calhoun, R., Valyou, D., Marzocca, P., Matthiesen, D., Brown, G., and Pryor, S. C.: 3D Wind and Turbulence Characteristics of the Atmospheric Boundary Layer, B Am. Meteorol. Soc., 95, 743-756, https://doi.org/10.1175/bamsd-12-00111.1, 2014.

Barthelmie, R. J., Doubrawa, P., Wang, H., Giroux, G., and Pryor, S. C.: Effects of an escarpment on flow parameters of relevance to wind turbines, Wind Energy, 19, 2271-2286, $2016 \mathrm{a}$.

Barthelmie, R. J., Doubrawa, P., Wang, H., and Pryor, S. C.: Defining wake characteristics from scanning and vertical fullscale lidar measurements, J. Phys. Conf. Ser., 753, 032034, https://doi.org/10.1088/1742-6596/753/3/032034, 2016b.

Barthelmie, R. J., Pryor, S. C., Wildmann, N., and Menke, R.: Wind turbine wake charcaterisation in complex terrain via in- 
tegrated Doppler lidar data from the Perdigao experiment, J. Phys. Conf. Ser., 1037, 052022, https://doi.org/10.1088/17426596/1037/5/052022, 2018.

Berg, J., Vasiljevic, N., Kelly, M., Lea, G., and Courtney, M.: Addressing Spatial Variability of Surface-Layer Wind with LongRange WindScanners, J. Atmos. Ocean. Tech., 32, 518-527, https://doi.org/10.1175/jtech-d-14-00123.1, 2015.

Bodini, N., Zardi, D., and Lundquist, J. K.: Threedimensional structure of wind turbine wakes as measured by scanning lidar, Atmos. Meas. Tech., 10, 2881-2896, https://doi.org/10.5194/amt-10-2881-2017, 2017.

Christiansen, M. B. and Hasager, C.: Wake effects of large offshore wind farms identified from satellite SAR, Remote Sens. Environ., 98, 251-268, 2005.

Clifton, A., Clive, P., Gottschall, J., Schlipf, D., Simley, E., Simmons, L., and Würth, I.: IEA Wind Task 32: Wind lidar identifying and mitigating barriers to the adoption of wind lidar, Remote Sens., 10, 406, https://doi.org/10.3390/rs10030406, 2018.

Coppin, P. A., Bradley, E. F., and Finnigan, J. J.: Measurements of flow over an elongated ridge and its thermal stability dependence: The mean field, Bound.-Lay. Meteor., 69, 173-199, https://doi.org/10.1007/bf00713302, 1994.

Doubrawa, P., Barthelmie, R. J., Wang, H., Pryor, S. C., and Churchfield, M.: Wind Turbine Wake Characterization from Temporally Disjunct 3-D Measurements, Remote Sens., 8, 939, https://doi.org/10.3390/rs8110939, 2016.

Doubrawa, P., Barthelmie, R. J., Wang, H., and Churchfield, M. J.: A stochastic wind turbine wake model based on new metrics for wake characterization, Wind Energy, 20, 449-463, https://doi.org/10.1002/we.2015, 2017.

Durran, D. R.: Mountain Waves and Downslope Winds, in: Atmospheric Process over Complex Terrain,, edited by: Blumen, W., American Meteorological Society, Boston, MA, 59-81, 1990.

El-Asha, S., Zhan, L., and Iungo, G. V.: Quantification of power losses due to wind turbine wake interactions through SCADA, meteorological and wind LiDAR data, Wind Energy, 20, 18231839, https://doi.org/10.1002/we.2123, 2017.

Emeis, S., Frank, H., and Fiedler, F.: Modification of air flow over an escarpment - results from the Hjardemal Experiment, Bound.Lay. Meteor., 74, 131-161, 1995.

Fernando, H. J. S., Mann, J., Palma, J. M. L. M., Lundquist, J. K., Barthelmie, R. J., BeloPereira, M., Brown, W. O. J., Chow, F. K., Gerz, T., Hocut, C. M., Klein, P. M., Leo, L. S., Matos, J. C., Oncley, S. P., Pryor, S. C., Bariteau, L., Bell, T. M., Bodin, I. N., Carney, M. B., Courtney, M., Creegan, E., Dimitrova, R., Gomes, S., Hagen, M., Hyde, O., Kigle, S., Krishnamurthy, R., Lopes, J. C., Mazzaro, L., Neher, J. M. T., Menke, R., Murphy, P., Oswald, L., Otarola-Bustos, S., Pattantyus, A. K., Rodrigues, C., Schady, A., Sirin, N., Spuler, S., Svensson, E., Tomaszewski, J., Turner, D. D., van Veen, L., Vasiljevic, N., Vassalo, D., Voss, S., Wildmann, N., and Wang, Y.: The Perdigão: Peering into Microscale Details of Mountain Winds, B. Am. Meteorol. Soc., May, 799$819,2019$.

Finnigan, J. and Belcher, S.: Flow over a hill covered with a plant canopy, Q. J. Roy. Meteorol. Soc., 130, 1-29, 2004.

Han, X., Liu, D., Xu, C., and Shen, W. Z.: Atmospheric stability and topography effects on wind turbine performance and wake properties in complex terrain, Renew. Energ., 126, 640 651, https://doi.org/10.1016/j.renene.2018.03.048, 2018.
Hunt, J. C. R., Richards, K. J., and Brighton, P. W. M.: Stably stratified shear flow over low hills, Q. J. Roy. Meteorol. Soc., 114, 859-886, https://doi.org/10.1002/qj.49711448203, 1988.

Iungo, G. V., Wu, Y.-T., and Porté-Agel, F.: Field measurements of wind turbine wakes with LiDARs, J. Atmos. Ocean. Tech., 30, 274-287, https://doi.org/10.1175/jtech-d-12-00051.1, 2013.

Jackson, P. and Hunt, J.: Turbulent wind flow over a low hill, Q. J. Roy. Meteorol. Soc., 101, 929-955, 1975.

Jensen, N. O.: A note on wind turbine interaction, Risø National Laboratory, Roskilde, Denmark, Ris $\emptyset-\mathrm{M}-2411,16,1983$.

Kaimal, J. C. and Finnigan, J. J.: Atmospheric Boundary Layer Flows: Their Structure and Measurement, Oxford University Press, New York, 289 pp., 1994.

Katic, I., Højstrup, J., and Jensen, N. O.: A simple model for cluster efficiency, European Wind Energy Association, Rome, 407-409, 1986.

Larsen, G. C., Madsen, H. A., Thomsen, K., and Larsen, T. J.: Wake meandering: a pragmatic approach, Wind Energy, 11, 377-395, https://doi.org/10.1002/we.267, 2008.

Letson, F., Barthelmie, R. J., Hu, W., and Pryor, S. C.: Characterizing wind gusts in complex terrain, Atmos. Chem. Phys., 19, 3797-3819, https://doi.org/10.5194/acp-19-3797-2019, 2019.

Machefaux, E., Larsen, G. C., Koblitz, T., Troldborg, N., Kelly, M. C., Chougule, A., Hansen, K. S., and Rodrigo, J. S.: An experimental and numerical study of the atmospheric stability impact on wind turbine wakes, Wind Energy, 19, 1785-1805, https://doi.org/10.1002/we.1950, 2016.

Mann, J., Angelou, N., Arnqvist, J., Callies, D., Cantero, E., Arroyo, R. C., Courtney, M., Cuxart, J., Dellwik, E., Gottschall, J., Ivanell, S., Kühn, P., Lea, G., Matos, J. C., Palma, J. M. L. M., Pauscher, L., Peña, A., Rodrigo, J. S., Söderberg, S., Vasiljevic, N., and Rodrigues, C. V.: Complex terrain experiments in the New European Wind Atlas, Philos. T. R. Soc. A, 375, 20160101, https://doi.org/10.1098/rsta.2016.0101, 2017.

Menke, R., Vasiljević, N., Mann, J., and Lundquist, J. K.: Characterization of flow recirculation zones at the Perdigão site using multi-lidar measurements, Atmos. Chem. Phys., 19, 2713-2723, https://doi.org/10.5194/acp-19-2713-2019, 2019.

Mikkelsen, T., Mann, J., Courtney, M., and Sjoholm, M.: Windscanner: 3-D wind and turbulence measurements from three steerable Doppler Lidars, in: 14th International Symposium for the Advancement of Boundary Layer Remote Sensing, edited by: Mann, J., Bingol, F., Courtney, M., Jorgensen, H. E., Lindelow, P., Mikkelsen, T., Pena, A., Sjoholm, M., and Wagner, R., IOP Conference Series-Earth and Environmental Science, 2008.

New European Wind Atlas data portal: available at: https:// perdigao.fe.up.pt/, last access: 30 August 2018.

Ohba, R., Hara, T., Nakamura, S., Ohya, Y., and Uchida, T.: Gas diffusion over an isolated hill under neutral, stable and unstable conditions, Atmos. Environ., 36, 5697-5707, https://doi.org/10.1016/S1352-2310(02)00642-8, 2002.

Pauscher, L., Vasiljevic, N., Callies, D., Lea, G., Mann, J., Klaas, T., Hieronimus, J., Gottschall, J., Schwesig, A., and Kühn, M.: An Inter-Comparison Study of Multi-and DBS Lidar Measurements in Complex Terrain, Remote Sens., 8, 782, https://doi.org/10.3390/rs8090782, 2016.

Pieterse, J. E. and Harms, T. M.: CFD investigation of the atmospheric boundary layer under different thermal stabil- 
ity conditions, J. Wind Eng. Ind. Aerod., 121, 82-97, https://doi.org/10.1016/j.jweia.2013.07.014, 2013.

Politis, E. S., Prospathopoulos, J., Cabezon, D., Hansen, K. S., Chaviaropoulos, P. K., and Barthelmie, R. J.: Modeling wake effects in large wind farms in complex terrain: the problem, the methods and the issues, Wind Energy, 15, 161-182, https://doi.org/10.1002/we.481, 2012.

Pryor, S. C., Barthelmie, R. J., and Shepherd, T.: The influence of real-world wind turbine deployments on regional climate, J. Geophys. Res.-Atmos., 123, 5804-5826, https://doi.org/10.1029/2017JD028114, 2018.

Risan, A., Lund, J., Chang, C.-Y., and Sætran, L.: Wind in Complex Terrain - Lidar Measurements for Evaluation of CFD Simulations, Remote Sens., 10, 59, https://doi.org/10.3390/rs10010059, 2018.

Sanz Rodrigo, J., Chávez Arroyo, R. A., Moriarty, P., Churchfield, M., Kosović, B., Réthoré, P. E., Hansen, K. S., Hahmann, A., Mirocha, J. D., and Rife, D.: Mesoscale to microscale wind farm flow modeling and evaluation, WIRES Energy. Environ., 6, e214, https://doi.org/10.1002/wene.214, 2017.

Smith, C. M., Barthelmie, R. J., and Pryor, S. C.: In situ observations of the influence of a large onshore wind farm on near-surface temperature, turbulence intensity and wind speed profiles, Environ. Res. Lett., 8, 034006, https://doi.org/10.1088/1748-9326/8/3/034006, 2013.

Stull, R. B.: An introduction to boundary layer meteorology, Kluwer Publications Ltd, Dordrecht, 666 pp., 1988.
Torres Garcia, E., Aubrun, S., Boquet, M., Royer, P., Coupiac, O., and Girard, N.: Wake meandering and its relationship with the incoming wind characteristics: a statistical approach applied to long-term on-field observations, IOP Conf. Series, J. Phys. Conf. Series, 854, 012045, https://doi.org/10.1088/17426596/854/1/012045, 2017.

Vasiljević, N., L. M. Palma, J. M., Angelou, N., Carlos Matos, J., Menke, R., Lea, G., Mann, J., Courtney, M., Frölen Ribeiro, L., and M. G. C. Gomes, V. M.: Perdigão 2015: methodology for atmospheric multi-Doppler lidar experiments, Atmos. Meas. Tech., 10, 3463-3483, https://doi.org/10.5194/amt-103463-2017, 2017.

Wang, H., Barthelmie, R. J., Clifton, A., and Pryor, S. C.: Wind measurements from arc scans with Doppler wind lidar, J. Atmos. Ocean. Tech. 32, 2024-2040, 2015.

Wang, H., Barthelmie, R. J., Pryor, S. C., and Brown, Gareth.: Lidar arc scan uncertainty reduction through scanning geometry optimization, Atmos. Meas. Tech., 9, 1653-1669, https://doi.org/10.5194/amt-9-1653-2016, 2016.

Whiteman, C. D. and Doran, J. C.: The relationship between overlying synoptic-scale flows and winds within in a valley, J. Appl. Meteorol., 32, 1669-1682, 1993.

Wildmann, N., Vasiljevic, N., and Gerz, T.: Wind turbine wake measurements with automatically adjusting scanning trajectories in a multi-Doppler lidar setup, Atmos. Meas. Tech., 11, 3801-3814, https://doi.org/10.5194/amt-11-3801-2018, 2018. 